Battery
Data

\begin{tabular}{|c|c|c|c|}
\hline \multicolumn{2}{|r|}{$\begin{array}{l}\text { Capacity Loss } \\
\text { Diagnostics }\end{array}$} & \multicolumn{2}{|c|}{ and Prognostics } \\
\hline$f_{\theta}$ & $\begin{array}{l}\text { Fraction of Active, Available Sites } \\
\text { (FAAS) in host material remaining } \\
\text { at time } t \text { for } \mathrm{Li}^{+} \text {charge transfer }\end{array}$ & $f_{L i^{+}}$ & $\begin{array}{l}\text { Fraction of Available } \mathrm{Li}^{+} \text {Inventory } \\
\text { (FALI) remaining at time } t \text { which } \\
\text { is a fraction of } \mathrm{Li}^{+} \text {within the bulk }\end{array}$ \\
\hline \multicolumn{2}{|c|}{$\begin{array}{l}\text { and intercalation; specific to charge or } \\
\text { discharge conditions. Diminished by: }\end{array}$} & \multirow{2}{*}{\multicolumn{2}{|c|}{$\begin{array}{l}\text { electrolyte, SEI, and solid particles (both } \\
\text { cathode and anode) that is available for } \\
\text { transport between electrodes. Can be } \\
\text { decreased through: }\end{array}$}} \\
\hline \multirow{2}{*}{\multicolumn{2}{|c|}{$\begin{array}{l}\text { 1. Permanent blockage of intercalation } \\
\text { pathways at particle surface, including } \\
\text { conductively-dead SEI. } \\
\text { 2. "Poisoning" of intercalation sites by } \\
\text { contaminants or by products from } \\
\text { irreversible chemical reactions. } \\
\text { 3. Mechanical degradation of solid state. } \\
\text { 4. Temporary (reversible) blockage of } \\
\text { intercalation pathways via phase transition } \\
\text { at particle interface. }\end{array}$}} & & \\
\hline & & \multicolumn{2}{|c|}{$\begin{array}{l}\text { 1. Irreversible consumption of } \mathrm{Li}^{+} \text {in } \mathrm{SEI} \text {. } \\
\text { 2. Irreversible consumption of } \mathrm{Li}^{+} \text {in other } \\
\text { side reactions, including formation of } \mathrm{Li}^{\circ} \text {. } \\
\text { 3. Reversible consumption of } \mathrm{Li}^{+} \text {in } \\
\text { temporary phase transitions as } \mathrm{f}(\mathrm{T}) \text {, e.g., } \\
\text { solid solvates. } \\
\text { 4. } \mathrm{Li}^{+} \text {trapped/sequestered in the solid state. }\end{array}$} \\
\hline \multicolumn{4}{|c|}{ We need both healthy FAAS and FALI for a Li-ion cell to function well. } \\
\hline
\end{tabular}




\title{
Novel Method for Evaluation and Prediction of Capacity Loss Metrics in Li-Ion Electrochemical Cells
}

\author{
Kevin L. Gering, $\mathrm{PhD}$
}

\begin{abstract}
Practical methods and metrics are needed to assist battery development and end-user communities in the area of battery aging, in particular, understanding capacity loss in Li-ion cells. Tools are sought that offer both diagnostic and prognostic benefits, while minimizing the need for prolonged testing or undue commitment of tangible resources. Based on a chemical engineering batch reactor approach to cell aging, this work is a move in the direction to meet such needs. Capacity loss is interpreted by a combination of sigmoidal rate expressions, having physically-meaningful parameters, which cover chief mechanisms that affect loss of available lithium and loss of active host material. A lithium source term is also accommodated by the modeling approach. Development is shown to identify reversible and irreversible capacity loss contributions, as well as calculate molar-based terms for lithium and active sites, and how these change over time due to cell aging. The method is demonstrated on NCA/graphite cell chemistries, where conditions of cycle-life, calendar-life, and temperature are considered. The resultant capability adds value toward deepening our understanding of aging contributions that impact capacity, and provides a foundation for improving Li-ion cell design and management through diagnostic and predictive elements.
\end{abstract}

Keywords: Capacity loss; lithium-ion cell; mechanistic analysis; reversible and irreversible losses; battery diagnostics and prognostics 


\begin{abstract}
Funding: This work was performed through support from the U.S. DOE Vehicle Technologies Program Office.
\end{abstract}

\title{
1. Introduction
}

Available capacity figures centrally into performance and health characterization of Li-ion cells over their service life. There are tandem needs for accurate interpretation of capacity at characterization conditions (cycling rate, temperature, etc.) and for robust self-consistent modeling techniques that can be used for diagnostic analysis of cell data as well as forecasting of future performance.

Degradation processes in rechargeable lithium-ion batteries vary in terms of time and length scales, and are very much dependent on the chosen cell chemistry. From a chemical engineering vantage point, each cell can be considered as a batch reactor wherein the reactants interact under the influence of temperature, heating/cooling rates, voltage potential, current density, and possible catalytic effects promoted at the electrode/SEI surfaces. True to the batch reactor precept, there is a thermodynamic limit to the extent of each contributing degradation mechanism as defined at the prevailing aging conditions.

Literature abounds in the area of battery aging, reflecting intense research worldwide as we seek Li-ion battery chemistries of improved longevity and performance. Reference work can be broken into rough categories: identification of aging mechanisms and related diagnostic methods [1-19], modeling involving mechanistic contributions, cycle-life conditions, and lifetime 
predictions [20-33], and chemistry-specific investigations of material fate such as for lithiated iron phosphate, LFP [20, 34-38].

Capacity loss in Li-ion cells is due to a combination of mechanisms, including loss of free available lithium, loss of active host sites, shifts in the potential-capacity curve, etc. Further distinctions can be made regarding contributions from irreversible and reversible capacity losses due to rate limitations. In the context herein, irreversible losses would involve consumption of free $\mathrm{Li}^{+}$through normal early-life formation of passivation films (SEI) as well as irreversible side reactions that continue over time, and would also include permanent loss or unavailability of active host material (and lithium trapped therein) due to a number of mechanical or physical mechanisms. Reversible losses are seen more under transport limitations such as cycle-induced polarization that causes a voltage limit to be reached before full capacity is realized. Lastly, some Li-ion cell chemistries exhibit a gain in capacity early in life due to a slow release of excess lithium as the cathode undergoes a thermodynamic transition to a more stable form. The robust method presented herein accounts for such lithium sources as a distinct mechanism for negative capacity loss. Although cell capacity can be viewed from both charge and discharge bases, the metric chosen herein is discharge capacity obtainable between upper and lower voltage limits, as it represents the electrochemical energy available within the battery to be used for power delivery. Charge and discharge capacities typically differ by a small margin (charge capacity being larger) due to cell inefficiencies and self-discharging, and both are sensitive to current density, temperature, and cell aging.

A modeling capability was developed that provides a kinetic rate analysis of the contributing factors to capacity loss and acts as a regression/prediction platform for cell performance. The 
modeling basis disclosed herein is a summation of self-consistent chemical kinetics rate expressions, where each covers a distinct mechanism (e.g., lithium loss), but collectively account for the net capacity loss over time for a particular characterization condition (allowance is also made for capacity gains). Specifically, sigmoid-based rate expressions are utilized to describe each contribution to capacity loss. Through additional mathematical development another tier of expressions is derived and used to perform differential analyses and segregate irreversible versus reversible contributions, as well as to determine molar concentration profiles over cell aging for affected $\mathrm{Li}^{+}$and active sites. Reversible fade components are surmised by comparing fade rates at $\mathrm{C}_{1} / 1$ versus $\mathrm{C}_{1} / 25$ conditions.

Multiple "Gen2" Li-ion cells of the 18650 configuration were tested at the INL under various conditions, including calendar-life (calL) and HEV-type cycle-life (cycL) testing [39]. As one example, baseline cells consisted of a $\mathrm{LiNi}_{0.8} \mathrm{Co}_{0.15} \mathrm{Al}_{0.05} \mathrm{O}_{2}$ cathode ( $35 \mu$ m laminate), a MAG10 carbon anode (also $35 \mu \mathrm{m}$ laminate), an electrolyte of a 3:7 mass ratio of EC to EMC with 1.2M $\mathrm{LiPF}_{6}$, and a 2300 series Celgard separator. Monthly reference performance tests (RPTs) performed at $25{ }^{\circ} \mathrm{C}$ covered static capacity $\left(\mathrm{C}_{1} / 1\right.$ and $\left.\mathrm{C}_{1} / 25\right)$, EIS, and pulsing at a scaled power goal. Baseline cells were defined at $60 \%$ state of charge (SOC) and $25{ }^{\circ} \mathrm{C}$, and were cycle-life tested for a total of 140 weeks, where on average they reached approximately $50 \%$ power fade, $16 \%$ capacity fade at $\mathrm{C}_{1} / 25$, and $32 \%$ capacity fade at $\mathrm{C}_{1} / 1$. Other cells having a slightly different cathode formulation (referred to as VARC) were also tested, covering different temperatures, calL and cycL conditions. The consequences of the test matrix on cell capacity losses are considered below. 
The capability described herein has applicability for both (i) stand-alone diagnostics, prognostics and design, and (ii) dynamic onboard or embedded monitoring systems that perform real-time evaluations on electrochemical cells in service within consumer electronics, grid applications, as well as EV, PHEV, and HEV vehicle applications.

\section{Theoretical Development}

In formulating mathematical descriptions of performance fade in lithium ion cells, it is an absolute necessity to have a clear conceptual basis of the related mechanisms. Perhaps the best starting point is to consider the links between aging initiators and cause/effect relationships (Fig. 1), which are at the heart of kinetic rate expressions that describe performance degradation. Initiators, or stress factors, are generally comprised of temperature and rate of temperature change, cell SOC or SOC range, charge and discharge cycling protocol, the presence of impurities (e.g., water) and combinations thereof. These promote the primary underlying causes of performance loss at an electrode, as (a) detrimental chemical reactions involving electrolyte that form films, precipitates, gases, etc., and (b) physical/mechanical changes in the electrode material (e.g., particle cracking and separation). The foremost effects from these causes are (a) the reduction of active charge transfer sites, (b) the reduction of active lithiation/intercalation sites, (c) loss of lithium ion inventory through conversion into insoluble forms or through sequestration within the degraded electrode material, (d) decrease of porosity with possible increase in tortuosity, (e) reduction of available pathways for lithium migration, (f) particle-toparticle separation, (g) electrode delamination. Of course, other minor cause and effect contributions could be mentioned, but those listed above are believed to have the most influence on performance degradation mechanisms. Effects are generally arranged in terms of what 
metric is being considered. For example, for capacity loss, there are distinct terms for (a) loss of lithium inventory, (b) loss of active host sites for lithium, and (c) gain in lithium inventory through gradual release from lithium-rich cathode systems. An indirect consideration would be how capacity becomes more rate-constrained from cell polarization as cells age, due in large measure to increased impedance.

The modeling basis herein provides diagnostic interpretation of the effects (or consequences, manifestations, etc.) for performance fade mechanisms, and has shown remarkable utility in datasets analyzed thus far. It provides comprehensive modeling of the data without selective exclusion of disagreeable values, and it provides an intelligent means of assessing the individual contributions that are unique to each cell chemistry. In describing aging processes, the model considers premier stress factors such as temperature, daily thermal cycling, cycling profile, SOC, change in SOC during cycling profile, extent of calendar-life conditions, etc. Lastly, the formalism provides an accurate analytical method for calculating the rates of each mechanism and overall observed degradation as a function of time and aging conditions. A related patent has been issued for this methodology [40].

To arrive at a meaningful description of the underlying causes and effects, the relational diagram could be represented as in Fig. 1. It seems reasonable that the most direct comparisons should be made between ( $\mathrm{A}$ and $\mathrm{B}$ ) and ( $\mathrm{C}$ and $\mathrm{D})$. That is, the "cause" side of the story would involve either a key representative reactant or reaction product, or mechanical process, whereas the effect side would relate something like the fraction of available active sites (FAAS) to an observed/measured performance parameter (alternately, the fraction of deactivated sites could be used). As such, a direct correlation would be understood between (A and B) and (C and D). 
There is an analogy between electrode-specific degradation mechanisms in lithium-ion cells and catalyst poisoning in heterogeneous catalysis. In a sense, a lithium-ion cell is similar to a batch catalytic reactor, because the electrode materials may act to promote the reactions involved in performance degradation, but become self-moderating as the consequence of the reactions is to diminish the active sites that promote the reactions. Thermodynamic constraints also influence the extent of such reactions. That is, the same active sites that promote charge transfer and lithiation/delithiation can also facilitate detrimental reactions. This degree of involvement between the net reactions and active sites will vary between electrode types and their chemical and physical characteristics. In many Li-ion chemistries the crystalline cathode materials can exhibit a strong, direct relationship (say, where the reaction product formation is pinpointed at the cathode active sites), whereas for the anode the relationship could be less direct and perhaps random (and thus, maybe weakly facilitated by the active host materials or not at all). Lastly, the theoretical extent of degradation is the result of a complex interplay of chemical kinetics, thermodynamics, available reactants within the closed (batch) system, and the cumulative test conditions experienced by the cell.

Through the approach herein it is possible to interpret the complex interplay of aging metrics, for example, the sensitivity between cell capacity, stress factors and rate limitations, and how much of power fade is due to capacity loss versus due to impedance rise. Again, these attributes are tied back to the starting materials and the various aging conditions encountered over time. To conclude, a rigorous method is offered to analyze chemistry-specific aging processes over a variety of stress factors, then utilize the diagnostic outcome for predictive evaluations. 


\title{
3. Mathematical Approach
}

\subsection{Foundational Relationships}

We start by defining two key terms related to cell capacity:

$f_{\theta} \quad$ Fraction of Active, Available Sites (FAAS) in host materials remaining at time $t$ for $\mathrm{Li}^{+}$charge transfer and intercalation; specific to charge or discharge conditions.

$f_{L i^{+}} \quad$ Fraction of Available Lithium Inventory (FALI) remaining at time $t$ which is fraction of $\mathrm{Li}^{+}$within the bulk electrolyte, SEI, and solid particles (both cathode and anode) that is available for transport between electrodes.

\begin{abstract}
We need both healthy FAAS and FALI for a Li-ion cell to function well. FAAS and FALI can both change over time, decreasing due to various mechanisms. These designations are aligned with literature consensus on capacity loss contributions sometimes referred to as loss of lithium inventory and loss of active material $[8,13,14,27,28,30]$.
\end{abstract}

Most probable mechanisms for degradation include:

FAAS: $\quad$ - $\quad$ Permanent blockage of intercalation pathways at particle surface, including conductively-dead SEI. 
- Poisoning" of intercalation sites by contaminants or by-products from irreversible chemical reactions.

- $\quad$ Mechanical degradation of solid state.

- $\quad$ Temporary (reversible) blockage of intercalation pathways via electrolyte phase transition at particle interface (low temperature).

FALI: $\quad$ - $\quad$ Irreversible consumption of $\mathrm{Li}^{+}$in SEI.

- $\quad$ Irreversible consumption of $\mathrm{Li}^{+}$in other side reactions, including formation of $L i^{\circ}$.

- $\quad$ Reversible consumption of $\mathrm{Li}^{+}$in temporary phase transitions as $\mathrm{f}(\mathrm{T})$, e.g., solid solvates.

- $\quad \mathrm{Li}^{+}$trapped/sequestered in the solid state.

We use the following definitions and notations

$$
\left[\begin{array}{l}
F A A S=f_{\theta} \equiv \frac{C_{\theta}(t, r, T, S O C)}{C_{\theta}^{0}(r, T, S O C)} \\
F A L I=f_{L i^{+}} \equiv \frac{C_{L i^{+}}(t, r, T, S O C)}{C_{L i^{+}}^{0}(r, T, S O C)}
\end{array}\right]_{i^{*}}
$$

for $C \equiv$ concentration scale, $i^{*} \equiv$ aging test condition, $r \equiv$ cycling rate used to assess capacity, $S O C \equiv$ target state of charge at $i^{*}$, and $T \equiv$ temperature. We then have

$$
\begin{aligned}
& \text { Fractional loss in FAAS over time } \equiv \Psi_{\theta}=1-f_{\theta} \\
& \text { Fractional loss in FALI over time } \equiv \Psi_{L i^{+}}=1-f_{L i^{+}}
\end{aligned}
$$


where superscript zero denotes a time-zero condition, and it is implied that all $f$ and $\Psi$ terms are functions of time except those denoted at zero time.

Also,

$$
\begin{aligned}
& \bar{\Psi}_{\theta}=\Psi_{\theta} \bar{f}_{\theta} \quad \text { where } \begin{aligned}
\bar{f}_{\theta} & \rightarrow 0 \text { as } C_{\theta}>>C_{L i^{+}} \\
& \rightarrow 1 \text { as } C_{\theta}<<C_{L i^{+}} \\
\bar{\Psi}_{L i^{+}}=\Psi_{L i^{+}} \bar{f}_{L i^{+}} & \text {where } \bar{f}_{L i^{+}} \rightarrow 0 \text { as } C_{\theta}<<C_{L i^{+}} \\
& \rightarrow 1 \text { as } C_{\theta}>>C_{L i^{+}}
\end{aligned}
\end{aligned}
$$

which simply states that the limiting concentration will dominate $\Psi$ behavior.

$$
\begin{aligned}
& \text { Obvious forms for } \bar{f}_{\theta}, \bar{f}_{L i^{+}} \text {are } \\
& \qquad \bar{f}_{\theta}=\frac{C_{L i^{+}}}{C_{\theta}+C_{L i^{+}}} ; \bar{f}_{L i^{+}}=\frac{C_{\theta}}{C_{\theta}+C_{L i^{+}}}
\end{aligned}
$$

These yield the correct trends and are bounded between 0 and 1 .

At $C_{\theta}=C_{L i^{+}}, \bar{f}_{\theta}=\bar{f}_{L i^{+}}=1 / 2$, saying that at this condition, both the active sites and $L i^{+}$play an equal part in determining $\Psi$, a correct result overall.

Thus, we have 
And the net loss at aging test condition $i$

$$
\Psi_{i^{*}}=\bar{\Psi}_{\theta}+\bar{\Psi}_{L i^{+}}=\left(\frac{C_{\theta}^{0}-C_{\theta}}{C_{\theta}^{0}}\right)\left(\frac{C_{L i^{+}}}{C_{\theta}+C_{L i^{+}}}\right)+\left(\frac{C_{L i^{+}}^{0}-C_{L i^{+}}}{C_{L i^{+}}^{0}}\right)\left(\frac{C_{\theta}}{C_{\theta}+C_{L i^{+}}}\right)
$$

These results are dependent on (time, capacity cycling rate, $\mathrm{T}_{i}, \mathrm{SOC}_{i}$ ), and whether charge or discharge is the capacity basis. We may also include a capacity source term (negative loss) if the cathode formulation possess a "lithium reserve" that becomes available over time [e.g., 41]

$$
\Psi_{i^{*}}=\bar{\Psi}_{\theta}+\bar{\Psi}_{L i^{+}}+\bar{\Psi}_{\text {source }}=\bar{\Psi}_{\theta}+\bar{\Psi}_{L i^{+}}+\bar{\Psi}_{\theta, \text { source }}+\bar{\Psi}_{L i^{+}, \text {source }}=\bar{\Psi}_{\theta, \text { net }}+\bar{\Psi}_{L i^{+}, \text {net }}
$$

From the preceding development, other useful forms can be derived, such as explicit expressions for the concentration terms

$$
\therefore \quad C_{\theta}=\frac{C_{L i^{+}}^{0} C_{\theta}^{0}\left(1-\Psi_{i^{*}}\right)}{C_{\theta}^{0} \bar{\Psi}_{\theta}+C_{L i^{+}}^{0}\left(1-\bar{\Psi}_{L i^{+}}\right)}
$$

and then

$$
C_{L i^{+}}=\frac{\alpha C_{\theta}}{(1-\alpha)}, \quad \text { where } \quad \alpha \equiv \frac{C_{\theta}^{0} \bar{\Psi}_{\theta}}{C_{\theta}^{0}-C_{\theta}}
$$




\subsection{Development of Sigmoidal-based Rate Expressions}

Sigmoid-based expressions were chosen as the basis for chemical kinetics (CK) rate expressions for the various capacity fade contributions since they accommodate salient physical/chemical parameters. Sigmoidal expressions carry several advantages in looking at complex phenomena over various domains, as they are robust, contain only three parameters, are easily differentiable, and highly accurate once reasonable estimates have been given for the parameters. They can also be combined (summed) to evaluate multiple mechanistic contributions to a phenomenon, denoted herein as the multiple sigmoid model (MSM). The sigmoidal plateau that develops at large time represents the thermodynamic equilibrium boundary for maximal extent of reaction within a batch reactor for the given set of test conditions, considering only those mechanisms included in the model. If aging conditions worsen over time, or additional capacity loss mechanisms become manifest much later in cell life, or if mechanisms become inter-dependent or second-order, then the plateau will increase accordingly but never past the theoretical maximum of 100 percent capacity loss. Collectively, these features insure that the resultant modeling capability has a relevant theoretical framework supported by a consistent mathematical basis (e.g., properly bounded) for the analysis of battery degradation processes. The generalized form of a single sigmoid expression covering an arbitrary performance attribute $\Psi_{\mathrm{j}, \mathrm{i}^{*}}$ affected by mechanism or process j under arbitrary system conditions $i^{*}$ is given as 
where response $\Psi_{\mathrm{j}, \mathrm{i}^{*}}$ is an observed performance attribute captured in box D in Fig. 1. Here, the expression is in terms of time $t$ as the independent variable, yet we could also write similar expressions for other independent domains. Mechanism or process $\mathrm{j}$ covers a distinct category of degradation phenomenon manifest from chemical reactions, physical/mechanical changes, thermodynamic phase behavior, etc. The variables in this expression are defined as

$$
\begin{aligned}
& a_{j}^{\prime}=\text { equivalent intrinsic "rate constant" for mechanism or process } j \text { that affects } \Psi_{j, i^{*}} \\
& b_{j}=\text { equivalent intrinsic kinetic order of process } j \\
& M_{j}=\text { Theoretical maximum extent of progression of process } j \text { under } i^{*} \\
& M_{j, o}=\text { Extent of progression of process } j \text { at time zero or other time reference. }
\end{aligned}
$$

As written, $\Psi_{\mathrm{j}, \mathrm{i}^{*}}$ is bounded between $\mathrm{M}_{\mathrm{j}, \mathrm{o}}$ and $\mathrm{M}_{\mathrm{j}}$. It should be noted that the (a,b,M) parameters are unique to the chosen system condition $i^{*}$. A change in $i^{*}$ (say, over time) necessitates re-evaluation of these parameters, since $i *$ is linked to the thermodynamic consequences of a given mechanism $\mathrm{j}$, and can influence the system to undergo another mechanism not directly attributable to j. Another form of Eq. (9a) has a different placement of the ' $a$ ' term in conjunction with the time variable:

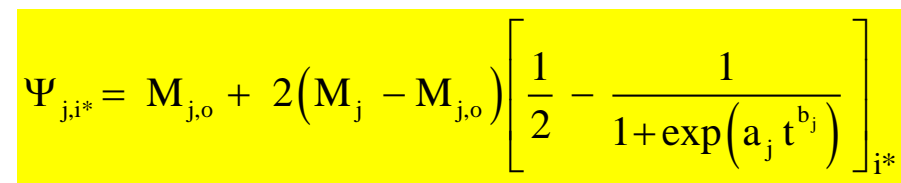


Eqs. (9a) and (9b) are functionally equivalent, but Eq. (9a) standardizes the units of 'a' to time ${ }^{-1}$. To ensure all $\mathrm{a}_{\mathrm{j}, \mathrm{i}^{*}}$ terms have consistent units of inverse time, the constituent terms in the $\mathrm{a}_{\mathrm{j}, \mathrm{i}^{*}}$ expression above must be converted beforehand to time ${ }^{-1}$ if they possess fractional units of time that differ according to the value of $b_{\mathrm{j}, \mathrm{i}}$ :

$$
\mathrm{a}_{\mathrm{j}, \mathrm{i}^{*}}^{\prime}=\left(\mathrm{a}_{\mathrm{j}, \mathrm{i}^{\mathrm{i}}}\right)^{\frac{1}{b_{\mathrm{j}, * *}}}
$$

The choice of sigmoidal rate expressions goes far beyond a satisfactory fit to data. The three sigmoidal parameters $(\mathrm{a}, \mathrm{b}, \mathrm{M})$ represent physical and thermodynamic terms for a given prevailing aging mechanism that reflect the progression of that mechanism in a batch reactor scenario under the conditions of aging. Well-sealed electrochemical cells are a form of batch reactor whose contents can interact and undergo modification depending on environmental and operational conditions. Thus, (a,b,M) reflect the physical reality of each aging mechanism, and these terms could be compared for similar batteries experiencing different aging conditions, and for different types of batteries experiencing identical aging conditions. Sigmoidal-based rate expressions such as Eqs.. (9a,b) and those below are well suited to describe the batch reaction kinetics that are observed in working batch reactors, where a near infinite variety of both hyperbolic and sigmoidal responses can be observed [42-45], and are feasible for interpretation within the MSM approach. Especially salient between MSM and batch reaction kinetics is the plateauing of the extent of forward reaction, which is a function of temperature and molar proportions of reactants [e.g., 42,43]. Similar behavior is observed in the extent of capacity loss in $\mathrm{Li}$-ion cells at 
prolonged aging, which generally increases with increasing temperature. Thus, the application

of sigmoidal-based mathematics toward battery aging mechanisms has a meaningful foundation.

Over prolonged time, battery aging can be affected by more than a single process. Per the MSM convention above, we extend Eq. (9a) to encompass a multitude of $\mathrm{n}$ simultaneous

processes

$$
\left.\Psi_{\mathrm{i}^{*}}=\sum_{\mathrm{j}}^{\mathrm{n}} \Psi_{\mathrm{j}, \mathrm{i}^{*}}=\sum_{\mathrm{j}}^{\mathrm{n}}\left[\mathrm{M}_{\mathrm{j}, \mathrm{o}}+2\left(\mathrm{M}_{\mathrm{j}}-\mathrm{M}_{\mathrm{j}, \mathrm{o}}\right)\left[\frac{1}{2}-\frac{1}{1+\exp \left(\left(\mathrm{a}_{\mathrm{j}}^{\prime} \mathrm{t}\right)^{\mathrm{b}_{\mathrm{j}}}\right)}\right]\right]_{\mathrm{i}^{*}}\right]
$$

which assumes the processes are reasonably independent, although alternative expressions can be derived for processes that are interdependent. The time derivative or rate of change in $\Psi_{\mathrm{i}^{*}}$ is given as follows

$$
\frac{d \Psi_{i^{*}}}{d t}=r_{i^{*}}^{M S M}=\frac{d}{d t}(M S M)_{i^{*}}=\sum_{j}\left[\frac{2\left(M_{j}-M_{j, o}\right) a_{j}^{\prime b_{j}} b_{j} t^{b_{j}-1} \exp \left(\left(a_{j}^{\prime} t\right)^{b_{j}}\right)}{\left(1+\exp \left(\left(a_{j}^{\prime} t\right)^{b_{j}}\right)\right)^{2}}\right]_{i^{*}}
$$

Much battery aging data found in the literature is defined at a single set of conditions over time for a particular group of cells, wherein $i^{*}$ is invariable. However, in practice the above expressions can be applied to each distinct aging period over time, so that the correct aging mechanisms and related MSM parameters are assessed over the operational and environmental conditions unique to each time period wherein these conditions are reasonably constant. For 
diagnostic analyses, this basis directly serves regression analysis that is used to determine the $(\mathrm{a}, \mathrm{b}, \mathrm{M})$ of each aging period. For prognostic analyses, this approach utilizes the determined $(a, b, M)$ to enable evaluation of aging over multiple successive aging periods to investigate the aspect of aging path dependence, which is the dedicated topic of a related paper.

Common sense should help guide regression of aging data. Regression analysis is a necessary first step in evaluation of aging data via MSM techniques wherein consistent and reliable methods are sought to enable the full power and accuracy of the method. For best results, mature datasets of high quality (low in both measurement error and cell-to-cell error) should be used to attain a satisfactory level of diagnostic knowledge and data confidence. Once MSM parameters have been obtained for all relevant mechanisms, they allow diagnostic analysis of the aging mechanisms and enable prediction of aging trends under existing aging test conditions or under some arbitrary conditions. However, as with any regression scheme, care must be had in understanding the limits or boundaries of the parameters for the system under study, and in guiding the regression scheme to avoid non-physical values of model parameters. The MSM method generally considers "bounded" data in terms of capacity, cell conductance, and power loss over time. That is, we know these each are bounded between 0 to 100 percent, with constituent mechanisms summing within that range. In many cases of Li-ion battery aging, the loss of lithium inventory dominates early capacity loss [8, 28, 35, 46, 47], and the sigmoidal parameters and computed quantities related to that mechanism can be easily estimated from relatively early data (e.g., Figs. 5 and 7). Once a rational choice of seed parameters is provided to the regression analysis, the MSM approach has shown itself to provide consistent interpretation of the data. As with any regression activity, a knowledgeable human agent is needed to interpret the ultimate outcome and weigh the attributes toward diagnostics and 
predictions. In this way, modeling techniques as those herein can assist in the scientific discovery

process. Regression is not a fully automated process since user discretion of the outcome is

always required regardless of the context. Experience is key to arrive at a consistent approach and to gain understanding of the behavior and utility of sigmoidal mathematics.

Per the terms above, our MSM capacity loss terms are defined for FAAS and FALI as

$$
\begin{gathered}
\bar{\Psi}_{\theta}=M_{\theta, o}+2\left(M_{\theta}-M_{\theta, o}\right)\left[\frac{1}{2}-\frac{1}{1+\exp \left(\left(a_{\theta}^{\prime} t\right)^{b_{\theta}}\right)}\right]_{i^{*}} \\
\bar{\Psi}_{L i^{+}}=M_{L i^{+}, o}+2\left(M_{L i^{+}}-M_{L i^{+}, o}\right)\left[\frac{1}{2}-\frac{1}{1+\exp \left(\left(a_{L i^{+}}^{\prime} t\right)^{b_{L i^{+}}}\right)}\right]_{i^{*}}
\end{gathered}
$$

\begin{abstract}
We may also include a MSM capacity source expression for materials that exhibit a lithium release over time.
\end{abstract}

\title{
3.3 Determination of Molar Quantities for FAAS and FALI
}

Combining Eqs. (5) and (13), we have linkages between physical quantities and analytical sigmoidal rate expressions 


$$
\begin{aligned}
& \bar{\Psi}_{\theta}=\left(1-\frac{C_{\theta}}{C_{\theta}^{0}}\right)\left(\frac{C_{L i^{+}}}{C_{\theta}+C_{L^{+}}}\right) \stackrel{!}{=} M_{\theta, o}+2\left(M_{\theta}-M_{\theta, o}\right)\left[\frac{1}{2}-\frac{1}{1+\exp \left(\left(a_{\theta}^{\prime} t\right)^{b_{\theta}}\right)}\right]_{i^{*}} \\
& \bar{\Psi}_{L i^{+}}=\left(1-\frac{C_{L i^{+}}}{C_{L i^{+}}^{0}}\right)\left(\frac{C_{\theta}}{C_{\theta}+C_{L i^{+}}}\right) \stackrel{!}{=} M_{L i^{+}, o}+2\left(M_{L i^{+}}-M_{L i^{+}, o}\right)\left[\frac{1}{2}-\frac{1}{1+\exp \left(\left(a_{L i^{+}}^{\prime} t\right)^{b^{+}}\right)}\right]_{i^{*}}
\end{aligned}
$$

\section{where the exclamation mark '!' over the equality sign denotes a defined or imposed equality.}

Since $\Psi_{i^{*}}$ represents the fractional decrease of battery performance (here, capacity) for

collective test conditions $i^{*}$, we wish to develop a rate expression(s) involving $\Psi_{i^{*}}$ and its

component members $\bar{\Psi}_{\theta}$ and $\bar{\Psi}_{L^{+}}$.

If we neglect a lithium source component, we have

$$
\begin{gathered}
\Psi_{i^{*}}=\left[\bar{\Psi}_{\theta}+\bar{\Psi}_{L i^{+}}\right]_{i^{*}} \\
{\left[r_{i^{*}}=\frac{d \Psi_{i^{*}}}{d t}=\frac{d \bar{\Psi}_{\theta}}{d t}+\frac{d \bar{\Psi}_{L i^{+}}}{d t}=r_{\theta}+r_{L i^{+}}\right]}
\end{gathered}
$$

where the differential rate forms are given in Eq. (12).

Through tandem consideration of Eq. (6), differential MSM rate terms, and 


$$
\frac{d \Psi_{i^{*}}}{d t}=\frac{d}{d t} \bar{\Psi}_{\theta}+\frac{d}{d t} \bar{\Psi}_{L i^{+}}=\frac{d}{d t}\left[\bar{\Psi}_{\theta}+\bar{\Psi}_{L i^{+}}\right]
$$

we can derive explicit interdependent expressions for lithium and active site concentrations. The mathematical development of these expressions is given in the Appendix.

\subsection{Irreversible and Reversible Capacity Loss Terms}

We now consider the determination of irreversible and reversible capacity losses.

Irreversible losses would involve consumption of free $\mathrm{Li}^{+}$through normal early-life SEI formation (as well as irreversible side reactions that continue over time), and would also include permanent loss or unavailability of active intercalative host material (and lithium therein) due to a number of mechanical or physical mechanisms. Reversible losses are seen more under transport limitations such as pulse-induced polarization that causes a voltage limit to be reached before full capacity is realized.

A baseline capacity is chosen as surmised at a low cycling rate $\left(r_{l o w}\right.$, say, $\left.\mathrm{C}_{1} / 25\right)$, and then used to look at the effective difference in concentration obtained at a higher rate (e.g., $\left.C_{1} / 1\right)$

$$
\begin{aligned}
& C_{\Delta \theta}=C_{\theta}\left(r_{\text {low }}\right)-C_{\theta}\left(r_{\text {high }}\right) \\
& C_{\Delta L i^{+}}=C_{L i^{+}}\left(r_{\text {low }}\right)-C_{L i^{+}}\left(r_{\text {high }}\right)
\end{aligned}
$$

Base (Irreversible) Changes: 


$$
\Psi_{\theta, \text { irrev }}=\frac{C_{\theta}^{0}-C_{\theta}\left(r_{\text {low }}\right)}{C_{\theta}^{0}} \quad ; \quad \Psi_{L i^{+}, \text {irrev }}=\frac{C_{L i^{+}}^{0}-C_{L i^{+}}\left(r_{\text {low }}\right)}{C_{L i^{+}}^{0}}
$$

Net (Irreversible and Reversible) Changes:

$$
\Psi_{\theta, \text { net }}=\frac{C_{\theta}^{0}-C_{\theta}\left(r_{\text {high }}\right)}{C_{\theta}^{0}} \quad ; \quad \Psi_{L i^{+}, \text {net }}=\frac{C_{L i^{+}}^{0}-C_{L i^{+}}\left(r_{\text {high }}\right)}{C_{L i^{+}}^{0}}
$$

Thus, reversible and impedance-related changes are:

$$
\begin{aligned}
& (\text { rev. }=\text { net }- \text { irrev. }) \\
& \Psi_{\theta, \text { rev }}=\left(\frac{C_{\theta}\left(r_{\text {low }}\right)-C_{\theta}\left(r_{\text {high }}\right)}{C_{\theta}^{0}}\right)_{i^{*}} \\
& =\left(\frac{C_{\Delta \theta}}{C_{\theta}^{0}}\right)_{i^{*}} \\
& \Psi_{L i^{+}, \text {rev }}=\left(\frac{C_{L i^{+}}\left(r_{\text {low }}\right)-C_{L i^{+}}\left(r_{\text {high }}\right)}{C_{L i^{+}}^{0}}\right)_{i^{*}} \\
& =\left(\frac{C_{\Delta L i^{+}}}{C_{L i^{+}}^{0}}\right)_{i^{*}}
\end{aligned}
$$

In general terms for Li-ion capacity 


$$
\begin{aligned}
\Psi_{i^{*}, \text { net }} & =\bar{\Psi}_{\theta, \text { net }}+\bar{\Psi}_{L i^{+}, \text {net }} \\
& =\left(\bar{\Psi}_{\theta, \text { rev }}+\bar{\Psi}_{\theta, \text { irrev }}\right)+\left(\bar{\Psi}_{L i^{+}, \text {rev }}+\bar{\Psi}_{L i^{+}, \text {irrev }}\right) \\
& =\left(\bar{\Psi}_{\theta, \text { irrev }}+\bar{\Psi}_{L i^{+}, \text {irrev }}\right)+\left(\bar{\Psi}_{\theta, \text { rev }}+\bar{\Psi}_{L i^{+}, \text {rev }}\right) \\
& =\left(\bar{\Psi}_{\theta, \text { irrev }}+\bar{\Psi}_{L i^{+}, \text {irrev }}\right)+\bar{\Psi}_{\text {rev }, \text { net }} \\
& =\Psi_{\text {irrev }, \text { net }}\left(r_{\text {low }}\right)+\bar{\Psi}_{\text {rev }, \text { net }}
\end{aligned}
$$

Thus, $\bar{\Psi}_{\text {rev,net }} \rightarrow 0$ as $r \rightarrow 0$.

Also, looking at the reversible loss due to cycling at a higher rate

$$
\begin{aligned}
\bar{\Psi}_{\text {rev }, \text { net }} & =\Psi_{i, \text { net }}\left(r_{\text {high }}\right)-\Psi_{i, \text { irrev }}\left(r_{\text {low }}\right) \\
& \bar{\Psi}_{\theta, \text { rev }}=\bar{\Psi}_{\theta, \text { net }}\left(r_{\text {high }}\right)-\Psi_{\theta, \text { irrev }}\left(r_{\text {low }}\right) \\
& \bar{\Psi}_{L i^{+}, \text {rev }}=\bar{\Psi}_{L i^{+}, \text {net }}\left(r_{\text {high }}\right)-\Psi_{L^{+}, \text {irrev }}\left(r_{\text {low }}\right)
\end{aligned}
$$

Terms with an overbar are referenced back to Eqs. (3-7).

Then

$$
\left[\begin{array}{l}
C_{\Delta \theta, r e v}=C_{\theta}\left(r_{\text {low }}\right)-C_{\theta}\left(r_{\text {high }}\right) \\
C_{\Delta L i^{+}, \text {rev }}=C_{L i^{+}}\left(r_{\text {low }}\right)-C_{L i^{+}}\left(r_{\text {high }}\right)
\end{array}\right]
$$

$$
\text { and }
$$

$$
\left[\Psi_{\theta, \text { rev }}=\frac{C_{\Delta \theta, \text { rev }}}{C_{\theta}^{0}} \quad \& \quad \Psi_{L i^{+}, \text {rev. }}=\frac{C_{\Delta L i^{+}, \text {rev }}}{C_{L i^{+}}^{0}}\right]
$$

and

$$
\left[\begin{array}{l}
r_{\theta, \text { rev }}\left(=\frac{d}{d t} \bar{\Psi}_{\theta, \text { rev }}\right)=r_{\theta, \text { net }}-r_{\theta, \text { irrev }}\left(=\frac{d}{d t} \bar{\Psi}_{\theta, \text { net }}-\frac{d}{d t} \bar{\Psi}_{\theta, \text { irrev }}\right) \\
r_{L i^{+}, \text {rev }}\left(=\frac{d}{d t} \bar{\Psi}_{L i^{+}, \text {rev }}\right)=r_{L i^{+}, \text {net }}-r_{L i^{+}, \text {irrev }}\left(=\frac{d}{d t} \bar{\Psi}_{L i^{+}, \text {net }}-\frac{d}{d t} \bar{\Psi}_{L i^{+}, \text {irrev }}\right)
\end{array}\right]
$$

Then for the rates of reversible components, based on the chemical kinetics molar concentration scale:

$$
\left[\begin{array}{l}
r_{C_{\Delta \theta, \text { rev }}}=\frac{d}{d t} C_{\Delta \theta, \text { rev }}=\frac{d}{d t} C_{\theta, \text { irrev }}-\frac{d}{d t} C_{\theta, \text { net }}=r_{C_{\theta, \text { net }}}-r_{C_{\theta, \text { irev }}} \\
r_{C_{\Delta i^{+}, \text {rev }}}=\frac{d}{d t} C_{\Delta L i^{+}, \text {rev }}=\frac{d}{d t} C_{L i^{+}, \text {irrev }}-\frac{d}{d t} C_{L i^{+}, \text {net }}=r_{C_{L i^{+}, \text {net }}}-r_{C_{L^{+}, \text {irev }}}
\end{array}\right]
$$




\subsection{Establishing Time-zero Values as Baseline Quantities}

Time-zero or beginning-of-life (BOL) is an important reference condition that figures centrally in the previous development. For example, concentration and related $\Psi$ terms might require an offset due to polarization effects experienced at higher cycling rates. A low-rate cycling condition (e.g., $\mathrm{r}_{\mathrm{low}}=\mathrm{C}_{1} / 25$ ) can be used to set the context for defining BOL terms, wherein an arbitrary cycling condition denoted by a $\left(\mathrm{r}^{*}\right)$ is considered:

$$
\Psi_{i^{*}}^{0}\left(r^{*}\right)=\frac{\Omega\left(r_{\text {low }}\right)-\Omega\left(r^{*}\right)}{\Omega\left(r_{\text {low }}\right)}
$$

where $\Omega$ is the BOL achievable capacity at the indicated rate for condition i. Following Eqs. $(3 a, b)$ and $(4 a, b)$ we have

$$
\bar{\Psi}_{\theta}^{0}\left(r^{*}\right)=\Psi_{i}^{0}\left(r^{*}\right)\left(\frac{C_{L^{+}}^{0}}{C_{\theta}^{0}+C_{L i^{+}}^{0}}\right)_{r_{\text {oow }}} \quad ; \quad \bar{\Psi}_{L i^{+}}^{0}\left(r^{*}\right)=\Psi_{i}^{0}\left(r^{*}\right)\left(\frac{C_{\theta}^{0}}{C_{\theta}^{0}+C_{L^{+}}^{0}}\right)_{r_{\text {low }}}
$$

We now offer another definition of BOL quantities at arbitrary $\mathrm{r}^{*}$, given for example for $\theta$ :

$$
\bar{\Psi}_{\theta}^{0}\left(r^{*}\right)=\left(\frac{C_{\theta}^{0}\left(r_{l o w}\right)-C_{\theta}^{0}\left(r^{*}\right)}{C_{\theta}^{0}\left(r_{\text {low }}\right)}\right) \quad \text { and likewise for } \bar{\Psi}_{L i^{+}}^{0}\left(r^{*}\right)
$$

Equating the previous two expressions for $\theta$ gives 


$$
C_{\theta}^{0}\left(r^{*}\right)=C_{\theta}^{0}\left(r_{\text {low }}\right)\left[1-\Psi_{i}^{0}\left(r^{*}\right)\left(\frac{C_{L i^{+}}^{0}}{C_{\theta}^{0}+C_{L i^{+}}^{0}}\right)_{r_{\text {low }}}\right] \quad \text { and likewise for } C_{L i^{+}}^{0}\left(r^{*}\right)
$$

Thus, relevant BOL values for concentration and related $\Psi$ terms can be estimated at an arbitrary cycling rate $\left(\mathrm{C}_{1} / 1, \mathrm{C}_{1} / 3,2 \mathrm{C}_{1}\right.$, etc.). In practice, these $\mathrm{BOL}$ values are incorporated into the generalized expressions, for example,

$$
\begin{aligned}
& \Psi_{i^{*}}\left(r^{*}\right)=\bar{\Psi}_{\theta}+\bar{\Psi}_{L i^{+}}+\bar{\Psi}_{\text {source }}+\Psi_{i}^{0}\left(r^{*}\right)=\bar{\Psi}_{\theta, \text { net }}+\bar{\Psi}_{L i^{+}, \text {net }} \\
& \text { e.g., } \quad \bar{\Psi}_{L i^{+}, \text {net }}=\bar{\Psi}_{L i^{+}, \text {loss }}+\bar{\Psi}_{L i^{+}, \text {source }}+\bar{\Psi}_{L i^{+}}^{0}\left(r^{*}\right)
\end{aligned}
$$

The low-rate cycling basis $\left(\mathrm{C}_{1} / 25\right)$ is chosen out of a compromise between timely measurement and the desire to obtain pseudo-equilibrium characterization. An additional basis can be adopted to look at a slower baseline (e.g., $\left.\mathrm{C}_{1} / 50\right)$ or the theoretical maximum "designrated" capacity, to see how far the $\mathrm{C}_{1} / 25$ basis differs with the theoretical baseline. This was done, wherein the method incorporates a design-rated theoretical baseline capacity at BOL to determine the unrecoverable capacity loss at BOL, due in good measure to the cell SEI formation process, at any cycling rate (results not shown herein).

\subsection{Criteria for Mechanistic Models of Transient Processes}

In developing sophisticated models that are increasingly aimed at capturing dynamic real phenomena in complex systems, it is necessary to evaluate the modeling capability against a set 
of relevant requirements for the intended application. What follows is a general summary of such requirements that we would consider for so-called mechanistic models.

\section{Mathematics:}

- $\quad$ is there a proper boundary condition represented at time zero $\left(\mathrm{t}_{0}\right)$ ?

- $\quad$ is there a proper boundary condition represented at large time $\left(\mathrm{t}_{\infty}\right)$ ?

- does the analytical form accurately correlate the data for the full range of conditions (robustness)?

- does the model possess adequate sophistication to capture subtle behavior in the data (rigor)?

- does the time-differentiated analytical form have proper boundary conditions at $\mathrm{t}_{0}$ and $\mathrm{t}_{\infty}$ ?

- does the time-differentiated analytical form faithfully correlate the rate data (differential test)?

- can the model variables be parameterized to reflect their dependency on the predominant test conditions?

Other:

- does the model format allow for a reasonable segregation of the predominant degradation mechanisms?

- can the overall modeling approach be used for predicting behavior past the extent of data (extrapolation)?

- can the overall modeling approach be used for predicting behavior between test conditions (interpolation)? 
- $\quad$ are pertinent thermodynamic considerations captured by the model; are geometric influences considered (e.g., particle sizes, electrode thickness, etc.)?

- $\quad$ can the model be easily validated with representative diagnostic data?

- do the model results add to our knowledge of the real system, or just restate this knowledge?

- $\quad$ is the model restricted to one type of data, or can it be applied more broadly?

It is proposed that the MSM approach makes solid steps forward in meeting most of these requirements as applied to Li-ion cell capacity loss. Regarding cases of extrapolation and interpolation, data can be split to use one part for deriving model parameters and the other part for model validation. For example, in extrapolating we would determine how much of the end of aging data could be omitted while still obtaining acceptable predictions past the earlier aging data. The MSM methodology has been applied in this way by the author, and it has been seen that in some cases the model provides high-fidelity predictions past the first half of data over the entire range of the second half (e.g., the aging over two years was ascertained with just the first year of data). This suggests that the application of this method would allow battery testing time to be significantly cut, thus supporting cost savings for technology testing and earlier market entry of new battery types.

There may indeed be cases where the application of a general modeling scheme is challenged by problematic data, such as cases where there is not a clear correlation of data between two distinct test conditions. Often, such cases reflect a fundamental difference of system response to the aging condition, as in thermodynamic phase behavior that might occur at lower temperatures, or gas formation in Li-ion cells that appears more manifest above a threshold temperature. Thus, "problematic data" may reflect the emergence of another 
mechanism that impacts battery performance and life, which must be clearly identified before its contributions to performance loss can be evaluated.

\section{Results and Discussion}

\subsection{Basis of Test Data for Analysis}

Lithium-ion cells of the spiral-wound 18650 configuration were manufactured by Quallion and tested under the DOE Advanced Technology Development (DOE-ATD) program, and were denoted as the Gen2 cell chemistry [39]. A variation in this chemistry (variation C or VARC) was also tested in tandem with the baseline Gen2 chemistry, and had a cathode with slight more aluminum ( 0.1 instead of 0.05 stoichiometry) and slightly less cobalt ( 0.1 instead of 0.15 stoichiometry). At the INL, cells were tested under a cycle-life (cycL) protocol, which was based on a scaled power goal (here, PNGV 25-Wh Power Assist Profile), wherein cells underwent short constant power discharge and charge pulses (about 10 seconds each) separated by rest periods, all centered at $60 \%$ SOC. This testing was performed continuously at either $25^{\circ} \mathrm{C}$ or $45^{\circ} \mathrm{C}$, using a test month of 28 days, with reference performance testing (RPT) after each 28-day period whereupon static capacity (C/25 and C/1), EIS, hybrid pulse power characterization (HPPC) and other metrics were measured at $25^{\circ} \mathrm{C}$. Several test months were covered in some cases. Testing was generally suspended when a cell reached $50 \%$ power fade. A comprehensive discussion of the Gen2 testing program and conditions mentioned above has been published in an INL report [39]. 


\subsection{Modeling Analyses Based on MSM Expressions}

Figures 2-9 summarize key aspects of capacity loss data and MSM results for the Gen2 cells, as obtained for data averaged over all cells at each test condition. All data shown is for discharge capacity, obtained by full discharge from $100 \%$ SOC to $0 \%$ SOC at the indicated cycling rate. Unless otherwise noted, MSM regression utilized a two-mechanism approach, including one sigmoid expression each for $\theta$ and $\mathrm{Li}^{+}$losses over time. In cases of $\mathrm{C}_{1} / 1$ capacity, the time-zero offset was included to account for the transport limitations that arise when going from a $C_{1} / 25$ rate to $C_{1} / 1$. MSM calculations were performed well past the extent of test data to allow for prognostic analyses.

Table 1 lists MSM parameters related to initial regression of test data based on Fig. 2, where it is seen that $b_{j}$ are reasonably consistent for each of the two main degradation mechanisms. Excluding an occasional outlier, the averages of $\mathrm{b}_{\mathrm{j}}$ for $\mathrm{Li}^{+}$and $\theta$-related mechanisms are 0.608 and 2.024 , respectively. This result strongly suggests that the reaction order terms can be assigned constant values over temperature and the aging condition. Since $\mathrm{b}_{\mathrm{j}}$ reflect the type of mechanism at work, then $b_{j}$ should remain constant insomuch as the mechanism types do not change between temperatures of interest. In the parlance of chemical kinetics the order of reaction is generally considered to be invariant over temperature if the mechanisms remain the same [48]. This approach was adopted to streamline management of MSM parameters over arbitrary aging conditions as would exist under PD scenarios, where $b_{\mathrm{Li+}}=0.6$ and $\mathrm{b}_{\theta}=2.0$ were chosen. Our MSM analyses of aging datasets covering other Li-ion cell chemistries have arrived at $b_{j}$ values remarkably similar to $(0.6,2.0)$. Based on these choices for $b_{j}$ the data represented in Table 1 was re-analyzed under a second-tier regression, and MSM parameters were re- 
determined. The result is shown in Table 2, which contains a compilation of MSM parameters for both calL and cycL aging data. Model parameters in Table 2 were then used to produce the modeling results given herein. Note that $M_{j, o}$ is zero for all cases in Tables 1 and 2 , since new cells were tested in the Gen2 trials. If previously aged cells are used (such as for a secondary use scenario) then non-zero $M_{j, o}$ would be utilized. Also of note is for the form of the ' $\mathrm{a}$ ' term in Tables 1 and 2; it is of the form related to Eq. (9b), but for general calculations it has been converted to the Eq. (9a) form via Eq. (10).

From Fig. 3 (a,b) it is seen that the MSM provides extremely high fidelity in capturing the data trends, with $\mathrm{R}^{2}$ values $\geq 0.9925$ in all cases. The model parameters in Table 2 are fine-tuned to the test conditions, and represent a clear connection between physical model parameters and the sensitivity of the cell chemistry to stress factors. Such accuracy allows a solid basis on which to perform diagnostic analyses for determining contributions from $\theta$ and $\mathrm{Li}^{+}$, reversible and irreversible contributions, and related quantities. Note that all MSM curves in Fig. 3 (a,b) exhibit extent of capacity fade $\left(\mathrm{M}_{\mathrm{j}}\right)$ less than $100 \%$ over prolonged time. This is reasonable when it is considered that chemical reaction processes in a batch system have kinetic and thermodynamic limitations uniquely related to choice of materials and test conditions, which ultimately affect the long-term extent of each mechanism. Figures 3 (c) and (d) show model results for timedependent capacity loss curves at various temperature ratios for calL and cycL conditions, respectively. Of interest is the tendency of the calL curves at $C_{1} / 1$ and $C_{1} / 25$ rates to converge over large time, whereas the cycL curves show divergence as 200 weeks is approached. This result suggests that calL conditions cause the relative rate of change in aging from the contributing mechanisms between 45 and $55^{\circ} \mathrm{C}$ to be more consistent over time, while the cycL 
conditions promote a greater temperature sensitivity within the aging mechanisms (more likely focused on loss of active sites), as observed at the slower-rate capacity in Fig. 3d.

Test data and MSM regression results for the VARC cells tested under cycle-life conditions of $45^{\circ} \mathrm{C}$ and $60 \%$ SOC are given in Fig. 4 . Table 1 contains values for the regression parameters. Overall, very good resolution of the test data is rendered by the modeling results, wherein small lithium source terms were included to establish the capacity loss trends. Thus, three-term MSM expressions were used to provide the results in Fig. 4 (per Eq. 7). As mentioned above, due to the specified cathode formulation, some Li-ion cell chemistries exhibit a relatively short-lived gain in capacity early in life due to a slow release of excess lithium as the cathode undergoes a thermodynamic transition to a more stable form. This gain mechanism can coincide with loss mechanisms for FALI and FAAS. The capacity loss data for VARC cells suggest this phenomenon is in effect, while showing more irreversible capacity than baseline cells. The BOL polarization offset is also a little higher for VARC cells compared to baseline, apparently due to impedance values that are roughly $12-15 \%$ higher than those of baseline cells [39].

Figure 5 (a) shows data for capacity fade at the $\mathrm{C}_{1} / 1$ condition for Gen 2 baseline cells cyclelife tested at $25^{\circ} \mathrm{C}$. Shown also are overall model results and the resultant segregation of capacity fade components due to free $\mathrm{Li}^{+}$loss and loss of active host sites. Recall that herein the term "loss" refers to net unavailability of $\mathrm{Li}^{+}$or sites, under the characterization condition, due to a host of mechanisms including consumption from reactions, physical/mechanical degradation of $\mathrm{Li}^{+}$ingress and egress paths, related transport limitations, etc. The initial offset in Fig. 5 is simply due to the difference in BOL capacity between $\mathrm{C}_{1} / 1$ and $\mathrm{C}_{1} / 25$ rates. It is seen that early capacity fade is tied more to net lithium loss mechanisms (as suspected), which tend to plateau 
early and are then eclipsed by mechanisms affecting active sites. Regarding the validation of timeline trends and magnitude of loss of lithium inventory and loss of active host materials, there is ample supporting evidence in the literature to support the general outcomes of this paper. For example, the work of Abraham, White, Ouyang, and the dQ/dV based work of Liaw give insights as the magnitude and manifestation of loss of lithium inventory, clearly showing it to be an early mechanism compared to loss of active material [8, 28, 35, 46, 47].

Figure 5 (b) includes the reversible and irreversible components to capacity loss at the $\mathrm{C}_{1} / 1$ characterization condition. Neglecting the BOL offset, irreversible losses of free $\mathrm{Li}^{+}$dominate during early testing ( $\leq 50$ weeks) while reversible losses of active sites dominate more over progressive time. One interpretation of Fig. 5 (b) is that a growing presence of reversible capacity loss is tied to irreversible losses, as these would represent the growth of higher impedance sources that would drive manifestation of polarization and related reversible losses. Overall, it is the capacity performance tied to active sites that dominates the effective capacity loss here, with both reversible and irreversible contributions growing at a diminishing rate at prolonged time.

For a batch system like a lithium-ion cell, the rates of chemical reactions that affect active sites depend on how many remaining active sites and reactants there are over time, since the active sites can facilitate, catalyze, or moderate these reactions. Thus, batch reactions that are reactant-promoted and product-moderated can be expected to manifest a sigmoid-type profile in the extent of reaction(s) involved. Regarding charge versus discharge performance, comparison of the charge and discharge capacities and related MSM parameters at a given cycling rate will 
give clear indications of which mode is more limiting over time in a kinetic sense, and whether such limitations are tied more to $\theta$ or $\mathrm{Li}^{+}$.

A comment is in order regarding distributed (locally-variant) capacity loss in Li-ion cells. Aging processes in Li-ion cells can manifest more in localities such as near electrode tabs where there could be greater heat generation during use [e.g., 49]. The extent to which local aging anomalies govern capacity loss is debatable and best considered on a case-by-case basis in terms of cell chemistry and use conditions. For example, there might be a greater possibility of local aging effects in larger-format prismatic cells as opposed to spiral-wound 18650 cells, keeping the current density and relative duty cycle the same. Among cells of very close manufacturing tolerance such as the Gen2 cells referenced herein, such local aging attributes would be similar among the cells. And, such local aging would still be governed by the conditions as captured in a batch scenario. This paper does not claim there is "homogeneous aging" throughout a given cell. Rather, it is suggested that the extent of capacity degradation, albeit tied somewhat to local effects, abides by the constraints of a batch reactor scenario. Thus, such distributed capacity fade is evaluated en masse with the present method, since the aging mechanisms are happening in concert within a closed chemical/mechanical system. The use of en masse or bulk analysis is not unusual for battery evaluations, as it is also employed extensively for impedance measurements such as DC resistance and EIS, where for the latter there is allowance for impedance attributes that reside perpendicular to an electrode surface (e.g., Nyquist analysis on a half-cell), but not quantified along its length. Finally, it is also possible to utilize the MSM basis to provide a zoneby-zone analysis of capacity loss within a cell, thereby capturing local effects. This approach would require additional laboratory data to validate the modeling outcome, and would be well suited for another paper. 
Figures 6 and 7 show analysis of molar concentration terms facilitated by the MSM approach per Eqs. (A.1-A.7). Such a quantitative analysis of capacity terms helps reveal conditions when cells become imbalanced in $\mathrm{Li}^{+}$and $\theta$. These cells appear to have been designed with a slightly greater molar proportion of active sites, which is a logical design approach to account for a greater loss of sites under cell aging. Estimates for BOL molar concentrations were determined from cell design specifications [39]. The modeling results show that loss of $\mathrm{Li}^{+}$is not greatly dependent on the characterization rate $\left(\mathrm{C}_{1} / 25\right.$ vs $\left.\mathrm{C}_{1} / 1\right)$, and yet loss of active sites is strongly dependent on rate. This suggests that loss of $\mathrm{Li}^{+}$occurs predominately as a surface phenomenon, while the sensitivity of loss of active sites to rate is due to constraints tied to slower threedimensional access to active host sites. As expected, Figs. 6 and 7 show molar-based capacity terms decrease with increasing temperature, while their time derivatives increase. Underlying this discussion is the effect of cell polarization at the $\mathrm{C}_{1} / 1$ rate to create reversible capacity "loss", as mentioned in the mathematical development given above. Studying the results of Figs. 6 and 7 help reveal the impact of polarization on the effective or realizable molar concentrations of $\mathrm{Li}^{+}$and $\theta$.

Figure 8 indicates the fraction of power fade due to cell conductance loss (at the hybrid-pulse power characterization or HPPC condition) and capacity loss. It is seen that the capacity contribution is at its greatest values at early testing life, and hence tracks with the irreversible loss of free $\mathrm{Li}^{+}$. This segregation is accomplished by subtracting from unity the ratio of conductance loss to power loss, which yields the capacity contribution to power loss: 


$$
\left(\begin{array}{l}
\text { Fraction of Power Loss } \\
\text { Due to Capacity Loss }(\mathrm{t})
\end{array}\right) \approx 1-\left(\frac{\text { Fractional Conductance Loss }(\mathrm{t})}{\text { Fractional Power Loss }(\mathrm{t})}\right)=1-\frac{\Psi_{\kappa}(\mathrm{t})}{\Psi_{P}(\mathrm{t})}
$$

where the ratio on the right-hand side indicates usage of MSM-based values for overall conductance loss and power loss over time. This expression is feasible since the HEV-based power pulses are short and relatively shallow [39], hence, reasonably independent of capacity loss (compared to impedance rise). It should be noted that the choice of the power goal will have some bearing on the relative contributions from conductance and capacity fades. A more general method is to define "performance fade" at an arbitrary power or current level, as is the basis of a related patent [50].

Figure 9 shows results from INL calendar-life testing of SAFT high-power cells, where these cells exhibited a lithium source over time, resulting in negative capacity loss under some conditions [51]. The MSM evaluation in Fig. 9 focuses on example cases that show evidence of capacity gain in the earlier test period. Such a lithium reserve is not unusual for some cathode types such as nickel-containing metal oxide composites [41]. A three-term MSM approach was used to provide the results in Fig. 9, as per Eq. (7).

To demonstrate the predictive capabilities of the MSM approach, two datasets were chosen to determine the fidelity of predictions when regression is based on early-life data. In Fig. 10, data for Gen2 $\mathrm{C} / 1$ and $\mathrm{C} / 25$ capacity at $25^{\circ} \mathrm{C}$ cycL testing serve as a basis for this demonstration, where approximately the first half of the original 140 weeks of data (Fig. 3) is used for each regression analysis. Regression starts with 68 weeks of data and incrementally moves up to 84 weeks. Regression parameters are based on a two-mechanism analysis, denoted 
as $(\mathrm{a}, \mathrm{b}, \mathrm{M})$ and $(\mathrm{c}, \mathrm{d}, \mathrm{N})$ for loss of lithium inventory and loss of active host material, respectively. As seed values for regression, $(\mathrm{a}, \mathrm{M}, \mathrm{c}, \mathrm{N})$ were given initial values of $(0.1,10,0.001,20)$, using SigmaPlot software Ver. 13.0 (Systat Software Inc.). For this study, b was set at 0.6 and d was set at 2.0 per Table 2 , as has been surmised by numerous other data sets for various Li-ion chemistries. Results indicate good predictive capability against the 140 week trend lines for both data sets. Small changes in the regression parameters are seen as regression progresses from 68 to 84 week of data, where parameter values align more closely with the 140 -week parameters along the way. The $\mathrm{C} / 25$ outcome has particularly high predictive capability, as the regression based early-life data is nearly indistinguishable with the 140-week trend line. Predictive outcome for the $\mathrm{C} / 1$ data is also good, but showing a little more variance in the $\mathrm{N}$ parameter, since $\mathrm{N}$ has a larger magnitude at the $\mathrm{C} / 1$ condition as seen in Fig. 5. The results in Fig. 10 are very encouraging for establishing this approach as a means to predict battery aging based on less data, with clear benefits of decreased testing time requirements and earlier market entry for new battery chemistries. Such a computational tool will aid in scientific discovery, engineering design, and decision making for advanced battery systems.

Some comments are in order regarding the plateau type behavior of capacity loss seen, for example, in Figs. 3 and 5. Plateauing of capacity loss data over time occurs for mature aging mechanisms, and it takes extended test times to capture such attributes. Reaction thermodynamics of closed systems dictates that the extent of the forward reaction can only proceed up to a limit that is driven by prevailing conditions. If those conditions are kept the same, such as for battery testing at set conditions, then it is logical to assume that thermodynamic consequences will determine the maximum extent of capacity loss. Again, this is more perceptible for mature data that represents longer-term testing. The plateau behavior seen in the 
MSM curves arises primarily because the independent MSM contributions are arriving toward their respective upper limits $\mathrm{M}_{\mathrm{j}}$ without additional mechanisms or complex interactions between mechanisms. If additional capacity loss mechanisms become manifest much later in cell life, or if mechanisms become inter-dependent or second-order, then the plateaus will increase accordingly within the effects of each unique aging test condition. Test data at greatly prolonged time would be required to establish whether the plateau trends are actually affected by additional mechanisms or nonlinear order of dependence of the $\theta$ and $\mathrm{Li}^{+}$contributions. The MSM formalism can then be adapted to this inter-dependence of mechanisms through expressions of the type

$\Psi_{i}^{\prime}=\left(\sum_{j}\left(1+f\left(\bar{\Psi}_{j}, \bar{\Psi}_{k}\right)\right)\right) \sum_{j} 2 M_{j}\left[\frac{1}{2}-\frac{1}{1+\exp \left(\left(a_{j}^{\prime} t\right)^{b_{j}}\right)}\right]_{i}$ for $j$ contributing mechanisms $(\mathrm{k} \neq \mathrm{j})$

or

$\Psi_{i}^{\prime}=\sum_{j}\left\{2 M_{j}\left[\frac{1}{2}-\frac{1}{1+\exp \left(\left(a_{j}^{\prime} t\right)^{b_{j}}\right)}\right]_{i}\left(1+f\left(\bar{\Psi}_{j}, \bar{\Psi}_{k}\right)\right)\right\}$ for $j$ contributing mechanisms $(\mathrm{k} \neq \mathrm{j})$

wherein the prime notation on $\Psi_{i}^{\prime}$ indicates these special cases of inter-dependent or nonlinear order of dependence of the primary contributions. The $f\left(\bar{\Psi}_{j}, \bar{\Psi}_{k}\right)$ term would likely be quantified through aging attributes from long-term testing, and can be served mathematically by several function types, most notably an exponential function that incorporates baseline thresholds for $\theta$ and $\mathrm{Li}^{+}$. 


\section{Conclusions}

A robust methodology has been demonstrated that allows diagnostic and prognostic analyses to be performed for capacity loss in Li-ion cells. The Multiple Sigmoid Model (MSM) enables mechanistic interpretations of capacity loss in Li-ion electrochemical systems, providing advantages over empirical methods in determining realistic contributions tied to the loss of effective capacity at arbitrary conditions. This methodology performs diagnostic analysis to provide key quantities central to understanding capacity loss in Li-ion electrochemical devices as a function of time, such as (1) Fraction of Active, Available Sites (FAAS, $\theta$ ), (2) Fraction of Available Lithium Inventory (FALI, $\left.\mathrm{Li}^{+}\right)$, (3) concentrations of these quantities, (4) reversible and irreversible contributions to these quantities, (5) rate expressions for these quantities, and (6) baseline values determined at beginning of life (BOL). A lithium source mechanism is also treated by the methodology. The generalized form of the MSM makes it amenable to analyzing any Li-ion dataset of capacity-over-time obtained at an arbitrary set of test conditions, and can provide predictive assessments of capacity fade once the parameters have been sufficiently trained with mature data trends. The method provides for incorporating a design-rated or theoretical baseline capacity at BOL to determine the unrecoverable (irreversible) and 
recoverable capacity losses at BOL at any cycling rate. Also, the predictive prowess of the MSM approach was demonstrated by utilizing roughly the first half of aging data to predict aging behavior over the second half of testing and beyond, with projected benefits for shortening the testing time for new batteries and allowing accelerated market entry.

This collective capability can be integrated into a scheme for Li-ion materials screening and technology improvement to mitigate the rate of loss of $\theta$ and $\mathrm{Li}^{+}$, and thus improve longevity of Li-ion cells. Applications for this capability abound in battery research and product development, and onboard monitoring of consumer electronics, battery power grid applications, and vehicle applications (e.g., electric vehicles (EV), hybrid electric vehicles (HEV), and plug-in hybrid electric vehicles (PHEV)). Collectively, these applications represent a multi-billion dollar industry. Lastly, the disclosed methodology is not limited to Li-ion application. The MSM formalism can be adapted to many other battery and non-battery applications wherein one or more time-dependent degradation mechanisms are operative.

\section{Acknowledgements}

This work was performed under the Advanced Technology Development (ATD) and Applied Battery Research (ABR) programs of the United States Department of Energy (DOE) under contract DE-AC07-05ID14517. The capability described herein is one of the featured elements included the INL software package CellSage. 


\section{Appendix: Derivation of Molar Concentration Terms}

We start by considering the separate terms:

$$
\begin{aligned}
\frac{d}{d t} \bar{\Psi}_{\theta} & =\frac{d}{d t}\left[\left(\frac{C_{\theta}^{0}-C_{\theta}}{C_{\theta}^{0}}\right)\left(\frac{C_{L i^{+}}}{C_{\theta}+C_{L i^{+}}}\right)\right] \stackrel{!}{=}\{\text { analytical value from MSM per Eq. (11) }\} \\
& =\frac{1}{C_{\theta}^{0}} \frac{d}{d t}\left[\frac{C_{\theta}^{0} C_{L i^{+}}-C_{\theta} C_{L i^{+}}}{C_{\theta}+C_{L i^{+}}}\right]
\end{aligned}
$$

Ratio Rule for derivatives:

$$
\frac{d}{d t}\left(\frac{u}{v}\right)=\frac{v \frac{d u}{d t}-u \frac{d v}{d t}}{v^{2}}
$$

which gives 


$$
\begin{aligned}
& \frac{d}{d t} \bar{\Psi}_{\theta}=\frac{1}{C_{\theta}^{0}}\left[\frac{\left(C_{\theta}+C_{L i^{+}}\right) \frac{d}{d t}\left(C_{\theta}^{0} C_{L i^{+}}-C_{\theta} C_{L i^{+}}\right)-\left(C_{\theta}^{0} C_{L i^{+}}-C_{\theta} C_{L i^{+}}\right) \frac{d}{d t}\left(C_{\theta}+C_{L i^{+}}\right)}{\left(C_{\theta}+C_{L i^{+}}\right)^{2}}\right] \\
& =\underbrace{\frac{1}{C_{\theta}^{0}\left(C_{\theta}+C_{L i^{+}}\right)^{2}}}_{\text {'由' }}[\overbrace{\left(C_{\theta}+C_{L^{+}}\right)}^{\text {'A' }^{\prime}}\left[C_{\theta}^{0} \frac{d}{d t} C_{L i^{+}}-\left(C_{\theta} \frac{d}{d t} C_{L i^{+}}+C_{L i^{+}} \frac{d}{d t} C_{\theta}\right)\right] \\
& -\underbrace{\left(C_{\theta}^{0} C_{L i^{+}}-C_{\theta} C_{L i^{+}}\right)}_{\text {'B' }}\left[\frac{d}{d t} C_{\theta}+\frac{d}{d t} C_{L i^{+}}\right]] \\
& =\frac{1}{\Phi}\left[\mathrm{A} C_{\theta}^{0} \frac{d C_{L L^{+}}}{d t}-\mathrm{A} C_{\theta} \frac{d C_{L i^{+}}}{d t}-\mathrm{A} C_{L i^{+}} \frac{d C_{\theta}}{d t}-\mathrm{B} \frac{d C_{\theta}}{d t}-\mathrm{B} \frac{d C_{L i^{+}}}{d t}\right] \\
& =\frac{1}{\Phi}[\frac{d C_{\theta}}{d t} \underbrace{\left(-\mathrm{A} C_{L i^{+}}-\mathrm{B}\right)}_{\alpha_{\theta}}+\frac{d C_{L L^{+}}}{d t} \underbrace{\left(\mathrm{A} C_{\theta}^{0}-\mathrm{A} C_{\theta}-\mathrm{B}\right)}_{\beta_{\theta}}] \\
& \therefore \quad\left[\frac{d \bar{\Psi}_{\theta}}{d t}=\frac{1}{\Phi}\left(\alpha_{\theta} \frac{d C_{\theta}}{d t}+\beta_{\theta} \frac{d C_{L^{+}}}{d t}\right)\right]
\end{aligned}
$$

Now, looking at $\frac{d}{d t} \bar{\Psi}_{L i^{+}}$:

$$
\begin{aligned}
\frac{d}{d t} \bar{\Psi}_{L i^{+}} & \left.=\frac{d}{d t}\left[\left(\frac{C_{L i^{+}}^{0}-C_{L i^{+}}}{C_{L i^{+}}^{0}}\right)\left(\frac{C_{\theta}}{C_{\theta}+C_{L i^{+}}}\right)\right] \stackrel{!}{=} \text { \{analytical value from MSM }\right\} \\
& =\frac{1}{C_{L i^{+}}^{0}} \frac{d}{d t}\left[\frac{C_{L i^{+}}^{0} C_{\theta}-C_{L i^{+}} C_{\theta}}{C_{\theta}+C_{L i^{+}}}\right]
\end{aligned}
$$

Applying Ratio Rule for derivatives: 


$$
\begin{aligned}
& \frac{d}{d t} \bar{\Psi}_{L i^{+}}=\frac{1}{C_{L i^{+}}^{0}}\left[\frac{\left(C_{\theta}+C_{L i^{+}}\right) \frac{d}{d t}\left(C_{L i^{+}}^{0} C_{\theta}-C_{L i^{+}} C_{\theta}\right)-\left(C_{L i^{+}}^{0} C_{\theta}-C_{L i^{+}} C_{\theta}\right) \frac{d}{d t}\left(C_{\theta}+C_{L i^{+}}\right)}{\left(C_{\theta}+C_{L i^{+}}\right)^{2}}\right] \\
& =\underbrace{\frac{1}{C_{L i^{+}}^{0}\left(C_{\theta}+C_{L i^{+}}\right)^{2}}}_{F^{\prime}}[\overbrace{\left(C_{\theta}+C_{L i^{+}}\right)}^{\mathrm{D} \mathrm{D}^{\prime}}\left[C_{L i^{+}}^{0} \frac{d C_{\theta}}{d t}-C_{L i^{+}} \frac{d C_{\theta}}{d t}-C_{\theta} \frac{d C_{L i^{+}}}{d t}\right] \\
& -\underbrace{\left(C_{L i^{+}}^{0} C_{\theta}-C_{L i^{+}} C_{\theta}\right)}_{' E^{\prime}}\left(\frac{d C_{\theta}}{d t}+\frac{d C_{L i^{+}}}{d t}\right)] \\
& =\frac{1}{F}\left[D C_{L i^{+}}^{0} \frac{d C_{\theta}}{d t}-D C_{L i^{+}} \frac{d C_{\theta}}{d t}-D C_{\theta} \frac{d C_{L i^{+}}}{d t}-E \frac{d C_{\theta}}{d t}-E \frac{d C_{L i^{+}}}{d t}\right] \\
& =\frac{1}{F}[\frac{d C_{\theta}}{d t} \underbrace{\left(D C_{L i^{+}}^{0}-D C_{L i^{+}}-E\right)}_{\alpha_{L i^{+}}}+\frac{d C_{L i^{+}}}{d t} \underbrace{\left(-D C_{\theta}-E\right)}_{\beta_{L i^{+}}}] \\
& \therefore \quad\left[\frac{d \bar{\Psi}_{L i^{+}}}{d t}=\frac{1}{F}\left(\alpha_{L i^{+}} \frac{d C_{\theta}}{d t}+\beta_{L i^{+}} \frac{d C_{L i^{+}}}{d t}\right)\right]
\end{aligned}
$$

Thus Equations (A.3) and (A.5) contain two unknowns: $\frac{d C_{\theta}}{d t}$ and $\frac{d C_{L i^{+}}}{d t}$

From (A.3):

$$
\left[\frac{d C_{\theta}}{d t}=\frac{1}{\alpha_{\theta}}\left(\Phi \frac{d \bar{\Psi}_{\theta}}{d t}-\beta_{\theta} \frac{d C_{L i^{+}}}{d t}\right)\right]
$$

Substitute (A.6) into (A.5) 


$$
\begin{aligned}
\frac{d \bar{\Psi}_{L i^{+}}}{d t}= & \frac{1}{F}\left(\alpha_{L i^{+}}\left[\frac{1}{\alpha_{\theta}}\left(\Phi \frac{d \bar{\Psi}_{\theta}}{d t}-\beta_{\theta} \frac{d C_{L i^{+}}}{d t}\right)\right]+\beta_{L i^{+}} \frac{d C_{L i^{+}}}{d t}\right) \\
\mathrm{F} \frac{d \bar{\Psi}_{L i^{+}}}{d t} & =\frac{\alpha_{L i^{+}}}{\alpha_{\theta}} \Phi \frac{d \bar{\Psi}_{\theta}}{d t}-\frac{\alpha_{L i^{+}}}{\alpha_{\theta}} \beta_{\theta} \frac{d C_{L i^{+}}}{d t}+\beta_{L i^{+}} \frac{d C_{L i^{+}}}{d t} \\
& =\frac{\alpha_{L i^{+}}}{\alpha_{\theta}} \Phi \frac{d \bar{\Psi}_{\theta}}{d t}+\frac{d C_{L i^{+}}}{d t}\left(\beta_{L i^{+}}-\frac{\alpha_{L i^{+}}}{\alpha_{\theta}} \beta_{\theta}\right) \\
\therefore\left[\frac{d C_{L i^{+}}}{d t}\right. & \left.=\left(\mathrm{F} \frac{d \bar{\Psi}_{L i^{+}}}{d t}-\frac{\alpha_{L i^{+}}}{\alpha_{\theta}} \Phi \frac{d \bar{\Psi}_{\theta}}{d t}\right)\left(\beta_{L i^{+}}-\frac{\alpha_{L i^{+}}}{\alpha_{\theta}} \beta_{\theta}\right)^{-1}\right]
\end{aligned}
$$

Then, $\frac{d C_{\theta}}{d t}$ is gotten by substituting Eq. (A.7) into Eq. (A.6). Recall that in this development, values for the differential terms of $\bar{\Psi}_{\theta}$ and $\bar{\Psi}_{L i^{+}}$are obtained via the MSM, then utilized in Eqs.
(A.3-A.7).

\section{References}

[1] M. Broussely, Ph. Biensan, F. Bonhomme, Ph. Blanchard, S. Herreyre, K. Nechev, R. J. Staniewicz, J. Power Sources 146 (2005) 90-96.

[2] A. Barré, B. Deguilhem, S. Grolleau, M. Gérard, F. Suard, D. Riu, J. Power Sources 241 (2013) 680-689.

[3] K. Gering, S. Sazhin, D. Jamison, C. Michelbacher, B. Y. Liaw, M. Dubarry, M. Cugnet, J. Power Sources 196 (2011) 3395-3403.

[4] D. Abraham, E. Reynolds, E. Sammann, A. Jansen, D. Dees, Electrochim. Acta 51, (2005) 502-510.

[5] J. Vetter, P. Novák, M. R. Wagner, C. Veit, K.-C. Möller, J. O. Besenhard, M. Winter, M. Wohlfahrt-Mehrens, C. Vogler, A. Hammouche, J. Power Sources 147 (2005)269-281.

[6] T. Osaka, S. Nakade, M. Rajamäki, T. Momma, J. Power Sources 119-121 (2003) 929-933.

[7] U. Tröltzsch, O. Kanoun, H.-R. Tränkler, Electrochim. Acta 51, (2006) 1664-1672.

[8] X. Han, M. Ouyang, L. Lu, J. Li, Y. Zheng, Z. Li, J. Power Sources 251 (2014) 38-54. 
[9] R. Jungst, G. Nagasubramanian, H. Case, B. Y. Liaw, A. Urbina, T. Paez, D. Doughty, J. Power Sources 119-121 (2003) 870-873.

[10] K. Asakura, M. Shimomura, T. Shodai, J. Power Sources 119-121 (2003) 902-905.

[11] M. Dubarry, V. Svoboda, R. Hwu, B. Y. Liaw, J. Power Sources 165 (2007) 566-572.

[12] M. Dubarry, V. Svoboda, R. Hwu, B. Y. Liaw, Electrochem. and Solid-State Letters 9 (2006) A454-A457.

[13] M. Dubarry and B. Y. Liaw, J. Power Sources 194 (2009) 541-549.

[14] M. Dubarry, C. Truchot, B. Y. Liaw, K. L. Gering, S. Sazhin, D. Jamison, C. Michelbacher, J. Electrochem. Soc. 160 (2013) A191-A199.

[15] M. Dubarry, V. Svoboda, R. Hwu, B. Y. Liaw, J. Power Sources 174 (2007) 1121-1125.

[16] K. Kumaresan, Q. Guo, P. Ramadass, R. White, J. Power Sources 158 (2006) 679-688.

[17] Y. Zhang and C.-Y. Wang, J. Electrochem. Soc. 156 (2009) A527-A535.

[18] K. Takeno, M. Ichimura, K. Takano, J. Yamaki, J. Power Sources 142 (2005) 298-305.

[19] S. Choi, H. Lim, J. Power Sources 111 (2002) 130-136.

[20] N. Omar, M. A. Monem, Y. Firouz, J. Salminen, J. Smekens, O. Hegazy, H. Gaulous, G. Mulder, P. Van den Bossche, T. Coosemans, J. Van Mierlo, Applied Energy 113 (2014) 1575-1585.

[21] A. Virkar, J. Power Sources 196 (2011) 5970-5984.

[22] H. Wenzl, I. Baring-Gould, R. Kaiser, B. Y. Liaw, P. Lundsager, J. Manwell, A. Ruddell, V. Svoboda, J. Power Sources 144 (2005) 373-384.

[23] Y. Liaw, R. Jungst, G. Nagasubramanian, H. Case, D. Doughty, J. Power Sources 140 (2005) 157-161.

[24] P. Ramadaas, B. Haran, P. Gomadam, R. White, B. Popov, J. Electrochem. Soc. 151 (2004) A196-A203.

[25] G. Sikha, B. Popov, R. White, J. Electrochem. Soc. 151 (2004) A1104-A1114.

[26] P. Arora, M. Doyle, R. White, Electrochem. Soc. Proc. 98-16 (1998) 553-572.

[27] Q. Zhang and R. White, J. Power Sources 179 (2008) 785-792.

[28] Q. Zhang and R. White, J. Power Sources 179 (2008) 793-798.

[29] G. Ning and B. Popov, J. Electrochem. Soc. 151 (2004) A1584-A1591.

[30] J. Christensen and J. Newman, J. Electrochem. Soc. 152 (2005) A818-A829.

[31] V. Agarwal, K. Uthaichana, R. DeCarlo, L. Tsoukalas, IEEE Trans. Energy Conv. 25 (2010) 821-835.

[32] Ecker, J. Gerschler, J. Vogel, S. Käbitz, F. Hust, P. Dechent, D. Sauer, J. Power Sources 215 (2012) 248-257.

[33] A. Schmidt, M. Bitzer, A. Imre, L. Guzzella, J. Power Sources 195 (2010) 7634-7638.

[34] A. Eddahech, O. Briat, J.-M. Vinassa, Energy 84 (2015) 542-550. 
[35] M. Dubarry, C. Truchot, B. Y. Liaw, J. Power Sources 258 (2014) 408-419.

[36] L. Ran, W. Jun-feng, W. Hai-ying, G. Jian-ying, L. Ge-chen, Information Sci. 259 (2014) 359-368.

[37] L. Saw, K. Somasundaram, Y. Ye, A. Tay, J. Power Sources 249 (2014) 231-238.

[38] P. Liu, J. Wang, J. Hicks-Garner, E. Sherman, S. Souklazlan, M. Verbrugge, H. Tataria, J. Musser, P. Finamore, J. Electrochem. Soc. 157 (2010) A499-A507.

[39] J. Christophersen, I. Bloom, E. Thomas, K. Gering, G. Henriksen, V. Battaglia, D. Howell, Gen2 Performance Evaluation Final Report, Idaho National Laboratory report INL/EXT05-00913 (July 2006). Available upon request.

[40] US Patent 8,467,984: "SYSTEMS, METHODS AND COMPUTER READABLE MEDIA FOR ESTIMATING CAPACITY LOSS IN RECHARGEABLE ELECTROCHEMICAL CELLS", Kevin L. Gering (June 18, 2013).

[41] M. Broussely, S. Herreyre, P. Biensan, P. Kasztejna, K. Nechev, R. Staniewicz, J. Power Sources 97-98 (2001) 13-21.

[42] M. S. Manjare, O. A. Deorukhkar, V. S. Sathe, Int. J. Adv. Tech. in Eng. and Sci. 3(1) (2015) 73-79.

[43] D. Darnoko and M. Cheryan, JAOCS 77 (12) (2000) 1263-1267.

[44] I. M. Mujtaba, N. Aziz and M. A. Hussain, Chem. Eng. Res. and Design 84(A8) (2006) 635-644.

[45] T. Fazekaš, A. Nagy and L. Treindl, Collect. Czech. Chem. Commun. 58 (1993) 775-782.

[46] Private communication, Daniel Abraham (Argonne National Lab) to Kevin Gering.

[47] M. Dubarry, C. Truchot, B. Y. Liaw, K. Gering, S. Sazhin, D. Jamison, and C. Michelbacher, J. Power Sources, 196 (2011) 10336-10343.

[48] C. G. Hill, An Introduction to Chemical Engineering Kinetics \& Reactor Design, John Wiley \& Sons, New York, 1977.

[49] K. Smith, E. Wood, S. Santhanagopalan, G. H. Kim, Y. Shi, A. Pesaran, "Predictive Models of Li-ion Battery Lifetime," Large Lithium Ion Battery Technology and Application Symposium (LLIBTA, 2015). ISBN: 978-1-5108-1146-1.

[50] US Patent 8,521,497: "SYSTEMS, METHODS AND COMPUTER-READABLE MEDIA FOR MODELING CELL PERFORMANCE FADE OF RECHARGEABLE ELECTROCHEMICAL DEVICES”, Kevin L. Gering (Aug. 27, 2013).

[51] Data used by permission from SAFT America (K. Nachev). 


\section{Table Captions}

Table 1: MSM parameters for regression of selected Gen2 data in Fig. 2.

Table 2: MSM parameters from second-tier regression of Gen2 lithium-ion baseline cell data covering calL and cycL conditions, setting $\mathrm{b}=0.6$ for $\mathrm{Li}^{+}$consumption-related mechanisms and $b=2.0$ for $\theta$-related mechanisms. In all cases $R^{2} \geq 0.9925$.

\section{Figure Captions}

Fig. 1: Relationships between stress factors, underlying causes, and various manifest effects for aging mechanisms in Li-ion cells.

Fig. 2. Summary of discharge capacity data for various Gen2 cells tested at INL under (a) cycle-life and (b) calendar-life conditions. Data: symbols; MSM: solid curves. Capacity values at BOL indicate the polarization offset due to the difference between $\mathrm{C}_{1} / 1$ and $\mathrm{C}_{1} / 25$ cycling rates.

Fig. 3. Analysis of discharge capacity fade data for the various Gen2 test conditions in Fig. 2: (a) calendar-life and (b) cycle-life conditions, with corresponding MSM regression results. Test data: symbols; MSM: solid curves. The $\mathrm{C}_{1} / 1$ values include the polarization offset due to the difference between $C_{1} / 1$ and $C_{1} / 25$ cycling rates. Figures (c) and (d) show model results for time-dependent capacity loss curves at various temperature ratios. All regression $\mathrm{R}^{2} \geq 0.9925$.

Fig. 4. Discharge capacity fade data for VARC cells tested at INL under cycle-life conditions of $45^{\circ} \mathrm{C}$ and $60 \%$ SOC, with corresponding MSM regression results. Test data: symbols; MSM results: solid curves. The $\mathrm{C}_{1}{ }_{1} / 1$ values include the polarization offset due to the difference between $C_{1} / 1$ and $C_{1} / 25$ cycling rates. Regression $\mathrm{R}^{2} \geq 0.988$ in all cases.

Fig. 5. Summary of $\mathrm{C}_{1} / 1$ capacity loss terms for Gen 2 cells cycle-life tested at $25^{\circ} \mathrm{C}$ and $60 \%$ SOC, showing (a) overall and mechanism-wise contributions and (b) irreversible and reversible contributions. Neglecting the BOL offset, irreversible losses dominate during early testing while reversible losses dominate later (well past the 140 week test period). Overall, it is the capacity performance tied to active sites that dominates the effective capacity loss here.

Fig. 6. Detailed analyses from MSM for Gen2 cells cycle-life tested at 25 and $45^{\circ} \mathrm{C}$ and $60 \%$ SOC, comparing $\mathrm{C}_{1} / 25$ and $\mathrm{C}_{1} / 1$ cycling rates. Shown are effective molar concentrations of $\theta$ and $\mathrm{Li}^{+}$(per FAAS and FALI). Model results span time periods roughly twice that of the corresponding test data. 
Fig. 7. Rate of change (time derivatives) of the concentration profiles shown in Fig. 5, from MSM analyses of Gen2 cells cycle-life tested at 25 and $45^{\circ} \mathrm{C}$ and $60 \%$ SOC, comparing $\mathrm{C}_{1} / 25$ and $\mathrm{C}_{1} / 1$ cycling rates. Model results span time periods roughly twice that of the corresponding test data.

Fig. 8. Additional analyses from MSM for Gen2 cells cycle-life tested at $45{ }^{\circ} \mathrm{C}$ and $60 \%$ SOC, showing the estimated fraction of cell power fade that is due to conductance and capacity losses.

Fig. 9. $\mathrm{C}_{1} / 1$ Capacity fade profiles and three-term MSM regression results for selected SAFT high-power cells tested at the INL under calendar-life conditions. Note that MSM results show particularly high fidelity to the data due to the inclusion of $\mathrm{a} \mathrm{Li}^{+}$source term. The data and modeling results indicate that this chemistry exhibits a lithium reserve over time.

Fig. 10. Results from testing the predictive capabilities of the MSM approach for two representative data sets (Gen2 $\mathrm{C} / 1$ and $\mathrm{C} / 25$ capacity at cycL testing at $25^{\circ} \mathrm{C}$ ). Approximately the first half of the original 140 weeks of data was used for each regression analysis, and results indicate good predictive capability against the 140 week trend lines for both data sets. Parameters ' $b$ ' and ' $d$ ' were set at 0.6 and 2.0, respectively, per Table 2 . 
Table 1: MSM parameters for regression of selected Gen2 data in Fig. 2.

\begin{tabular}{|c|c|c|c|c|c|c|}
\hline Aging Test Condition & $\begin{array}{l}\text { Cycling } \\
\text { Rate }\end{array}$ & $\mathbf{j}$ & $\begin{array}{c}\mathbf{a}_{\mathbf{j}} \\
{\left[\text { weeks }^{-b_{j}}\right]}\end{array}$ & $\mathbf{b}_{\mathbf{j}}$ & $\begin{array}{l}\mathbf{M}_{\mathbf{j}} \\
{[\%]}\end{array}$ & $\begin{array}{c}\text { Test data } \\
\text { range (wks) }\end{array}$ \\
\hline \multirow{2}{*}{$\begin{array}{l}\text { cycL at } 25^{\circ} \mathrm{C}, 60 \% \mathrm{SOC} \\
\text { (baseline cells) }\end{array}$} & \multirow{2}{*}{$\mathrm{C}_{1} / 25$} & $\theta$ & $1.564 \times 10^{-4}$ & 1.6763 & 34.1035 & 140 \\
\hline & & $\mathrm{Li}^{+}$ & 0.3520 & 0.6211 & 5.8965 & 140 \\
\hline \multirow{2}{*}{$\begin{array}{l}\text { cycL at } 45^{\circ} \mathrm{C}, 60 \% \mathrm{SOC} \\
\text { (baseline cells) }\end{array}$} & \multirow{2}{*}{$\mathrm{C}_{1} / 25$} & $\theta$ & $4.535 \times 10^{-5}$ & 2.1787 & 36.363 & 68 \\
\hline & & $\mathrm{Li}^{+}$ & 0.4409 & 0.4993 & 13.000 & 68 \\
\hline \multirow{3}{*}{$\begin{array}{l}\text { cycL at } 45^{\circ} \mathrm{C}, 60 \% \mathrm{SOC} \\
\text { (VARC cells) }\end{array}$} & \multirow{3}{*}{$\mathrm{C}_{1} / 25$} & $\theta$ & $6.465 \times 10^{-5}$ & 1.9112 & 26.000 & 124 \\
\hline & & $\mathrm{Li}^{+}$ & 0.1381 & 0.6698 & 12.000 & 124 \\
\hline & & source & $8.632 \times 10^{-7}$ & 3.960 & -2.4227 & 124 \\
\hline \multirow{2}{*}{$\begin{array}{l}\text { cycL at } 25^{\circ} \mathrm{C}, 60 \% \mathrm{SOC} \\
\text { (baseline cells) }\end{array}$} & \multirow{2}{*}{$\mathrm{C}_{1} / 1$} & $\theta$ & $1.856 \times 10^{-5}$ & 2.3662 & $\begin{array}{l}31.9019 \\
(+8.73)^{*}\end{array}$ & 140 \\
\hline & & $\mathrm{Li}^{+}$ & 0.3750 & 0.6994 & $\begin{array}{c}5.0981 \\
(+8.73)^{*}\end{array}$ & 140 \\
\hline \multirow{2}{*}{$\begin{array}{l}\text { cycL at } 45^{\circ} \mathrm{C}, 60 \% \mathrm{SOC} \\
\text { (baseline cells) }\end{array}$} & \multirow{2}{*}{$\mathrm{C}_{1} / 1$} & $\theta$ & $5.115 \times 10^{-6}$ & 3.0368 & $\begin{array}{c}25.000 \\
(+9.18)^{*}\end{array}$ & 68 \\
\hline & & $\mathrm{Li}^{+}$ & 0.3507 & 0.4373 & $\begin{array}{c}11.000 \\
(+9.18)^{*}\end{array}$ & 68 \\
\hline \multirow{3}{*}{$\begin{array}{l}\text { cycL at } 45^{\circ} \mathrm{C}, 60 \% \mathrm{SOC} \\
\text { (VARC cells) }\end{array}$} & \multirow{3}{*}{$\mathrm{C}_{1} / 1$} & $\theta$ & $4.220 \times 10^{-5}$ & 2.0833 & $\begin{array}{c}22.0972 \\
(+15.35)^{*}\end{array}$ & 124 \\
\hline & & $\mathrm{Li}^{+}$ & 0.1011 & 0.7220 & $\begin{array}{c}10.7722 \\
(+15.35)^{*}\end{array}$ & 124 \\
\hline & & source & $1.745 \times 10^{-3}$ & 1.9282 & -5.7582 & 124 \\
\hline
\end{tabular}

* Applicable BOL net offset due to C/1 polarization effects, covering collective mechanisms. 
Table 2: MSM parameters from second-tier regression of Gen2 lithium-ion baseline cell data covering calL and cycL conditions, setting $b=0.6$ for $\mathrm{Li}^{+}$consumption-related mechanisms and $b=2.0$ for $\theta$-related mechanisms. In all cases $\mathrm{R}^{2} \geq 0.9925$.

\begin{tabular}{|c|c|c|c|c|c|c|}
\hline Aging Test Condition & $\begin{array}{c}\text { Cycling } \\
\text { Rate }\end{array}$ & $\mathbf{j}$ & $\begin{array}{c}\mathbf{a}_{\mathbf{j}} \\
{\left[\text { weeks }^{-b_{j}}\right]}\end{array}$ & $\mathbf{b}_{\mathbf{j}}$ & $\begin{array}{c}\mathbf{M}_{\mathbf{j}} \\
{[\%]}\end{array}$ & $\begin{array}{c}\text { Test data } \\
\text { range (wks) }\end{array}$ \\
\hline \multicolumn{7}{|c|}{ Cycle-life Aging Conditions } \\
\hline \multirow[b]{2}{*}{ cycL at $25^{\circ} \mathrm{C}, 60 \% \mathrm{SOC}$} & \multirow[b]{2}{*}{$\mathrm{C}_{1} / 25$} & $\theta$ & $6.670 \times 10^{-5}$ & 2.0 & 16.41 & 140 \\
\hline & & $\mathrm{Li}^{+}$ & 0.3211 & 0.6 & 6.641 & 140 \\
\hline \multirow[b]{2}{*}{ cycL at $45^{\circ} \mathrm{C}, 60 \% \mathrm{SOC}$} & \multirow[b]{2}{*}{$\mathrm{C}_{1} / 25$} & $\theta$ & $8.007 \times 10^{-5}$ & 2.0 & 50.58 & 68 \\
\hline & & $\mathrm{Li}^{+}$ & 0.4347 & 0.6 & 11.14 & 68 \\
\hline \multirow{2}{*}{ cycL at $25^{\circ} \mathrm{C}, 60 \% \mathrm{SOC}$} & \multirow{2}{*}{$\mathrm{C}_{1} / 1$} & $\theta$ & $8.559 \times 10^{-5}$ & 2.0 & $\begin{array}{c}42.74 \\
(+8.73) *\end{array}$ & 140 \\
\hline & & $\mathrm{Li}^{+}$ & 0.6885 & 0.6 & $\begin{array}{c}4.496 \\
(+8.73)^{*} \\
\end{array}$ & 140 \\
\hline \multirow{2}{*}{ cycL at $45^{\circ} \mathrm{C}, 60 \% \mathrm{SOC}$} & \multirow{2}{*}{$\mathrm{C}_{1} / 1$} & $\theta$ & $1.604 \times 10^{-4}$ & 2.0 & $\begin{array}{c}70.00 \\
(+9.18)^{*}\end{array}$ & 68 \\
\hline & & $\mathrm{Li}^{+}$ & 0.8414 & 0.6 & $\begin{array}{c}5.111 \\
(+9.18)^{*} \\
\end{array}$ & 68 \\
\hline \multicolumn{7}{|c|}{ Calendar-life Aging Conditions } \\
\hline \multirow[b]{2}{*}{ calL at $45^{\circ} \mathrm{C}, 60 \% \mathrm{SOC}$} & \multirow[b]{2}{*}{$\mathrm{C}_{1} / 25$} & $\theta$ & $5.406 \times 10^{-5}$ & 2.0 & 52.27 & 88 \\
\hline & & $\mathrm{Li}^{+}$ & 0.3000 & 0.6 & 14.34 & 88 \\
\hline \multirow{2}{*}{ calL at $55^{\circ} \mathrm{C}, 60 \% \mathrm{SOC}$} & \multirow[b]{2}{*}{$\mathrm{C}_{1} / 25$} & $\theta$ & $1.171 \times 10^{-4}$ & 2.0 & 58.52 & 40 \\
\hline & & $\mathrm{Li}^{+}$ & 0.3819 & 0.6 & 16.99 & 40 \\
\hline \multirow{2}{*}{ calL at $45^{\circ} \mathrm{C}, 60 \% \mathrm{SOC}$} & \multirow{2}{*}{$\mathrm{C}_{1} / 1$} & $\theta$ & $1.191 \times 10^{-4}$ & 2.0 & $\begin{array}{c}70.00 \\
(+4.54)^{*}\end{array}$ & 88 \\
\hline & & $\mathrm{Li}^{+}$ & 0.3242 & 0.6 & $\begin{array}{c}4.200 \\
(+4.54)^{*}\end{array}$ & 88 \\
\hline \multirow{2}{*}{ calL at $55^{\circ} \mathrm{C}, 60 \% \mathrm{SOC}$} & \multirow{2}{*}{$\mathrm{C}_{1} / 1$} & $\theta$ & $1.806 \times 10^{-4}$ & 2.0 & $\begin{array}{c}72.00 \\
(+4.54)^{*}\end{array}$ & 40 \\
\hline & & $\mathrm{Li}^{+}$ & 0.4342 & 0.6 & $\begin{array}{c}7.750 \\
(+4.54)^{*} \\
\end{array}$ & 40 \\
\hline
\end{tabular}

* Applicable BOL net offset due to $\mathrm{C} / 1$ polarization effects, covering collective mechanisms. 


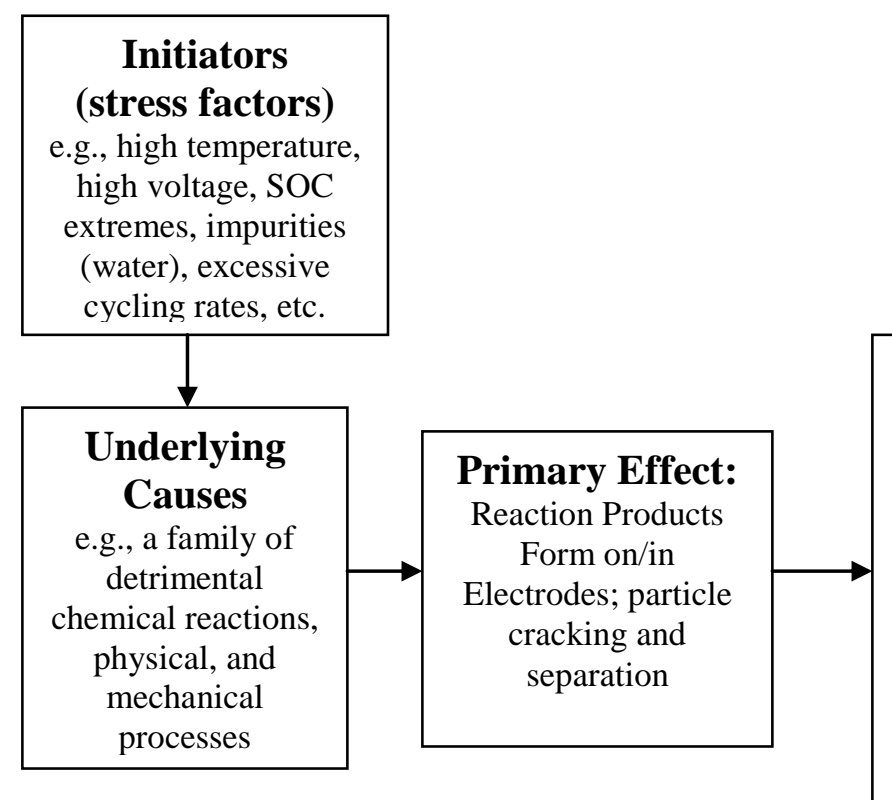

(A)
(B)

\begin{tabular}{|c|c|}
$\begin{array}{c}\text { Secondary } \\
\text { Effect: } \\
\text { Reduction of } \\
\text { Available Active } \\
\text { Sites on/in } \\
\text { Electrodes; } \\
\text { decreased porosity, } \\
\text { increased } \\
\text { tortuosity; } \\
\text { decreased } \\
\text { conductivity }\end{array} \quad \begin{array}{c}\text { Observed } \\
\text { Effects: } \\
\text { Reduction of } \\
\text { Performance Metrics } \\
\text { (e.g., capacity, } \\
\text { available power) }\end{array}$ \\
\hline
\end{tabular}

(C)

(D)

Fig. 1: Relationships between stress factors, underlying causes, and various manifest effects for aging mechanisms in Li-ion cells. 

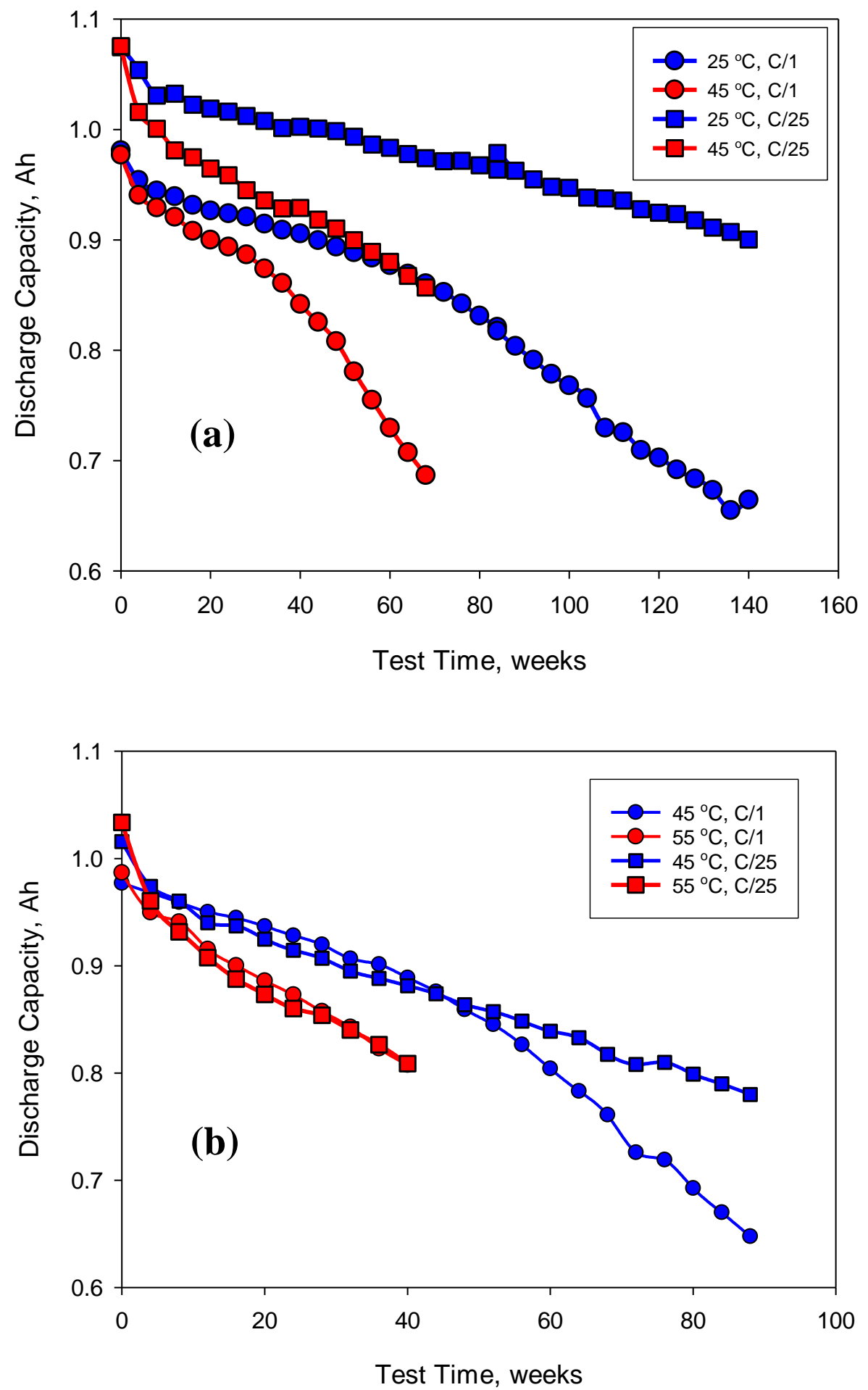

Fig. 2. Summary of discharge capacity data for various Gen2 cells tested at INL under (a) cycle-life and (b) calendar-life conditions. Data: symbols; MSM: solid curves. Capacity values at $\mathrm{BOL}$ indicate the polarization offset due to the difference between $\mathrm{C}_{1} / 1$ and $\mathrm{C}_{1} / 25$ cycling rates. 

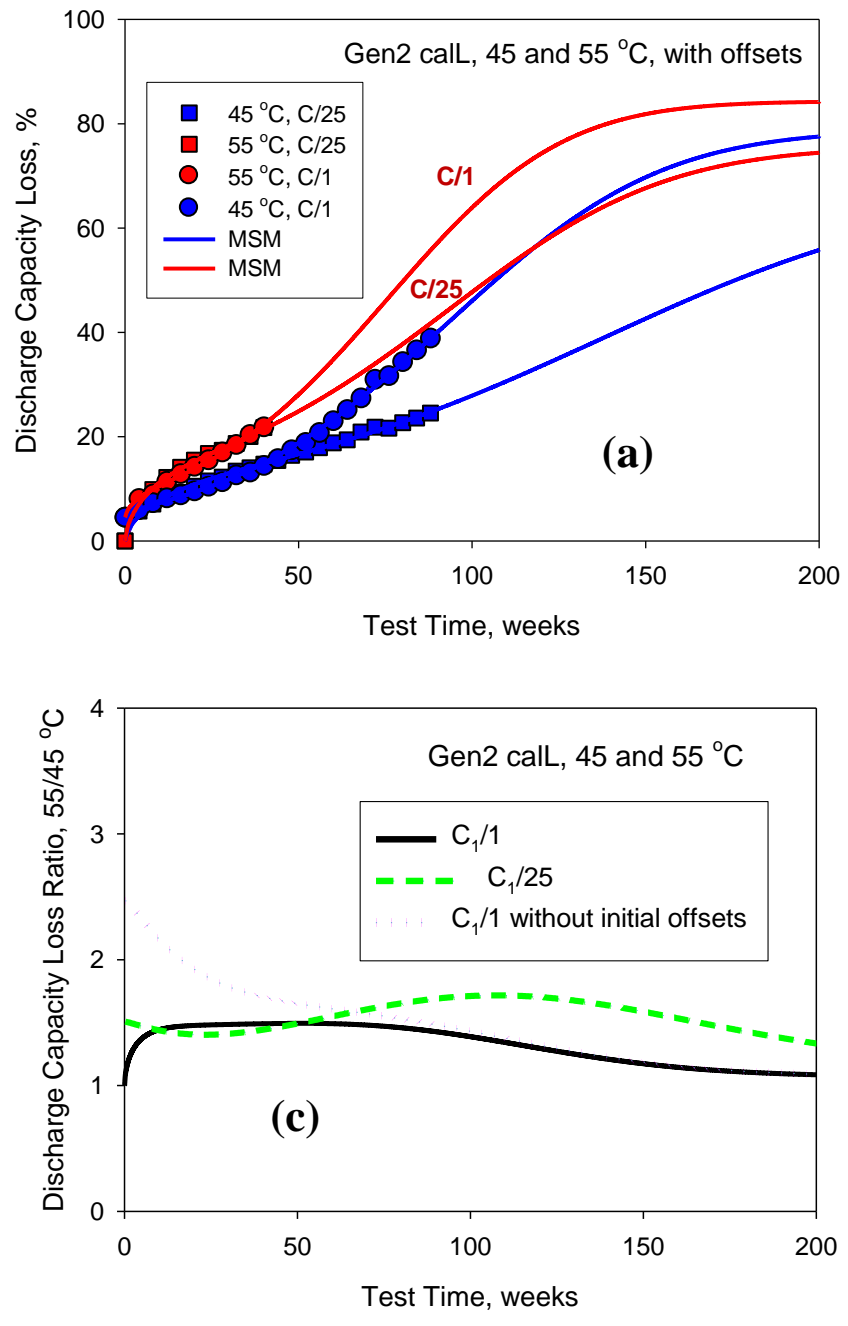
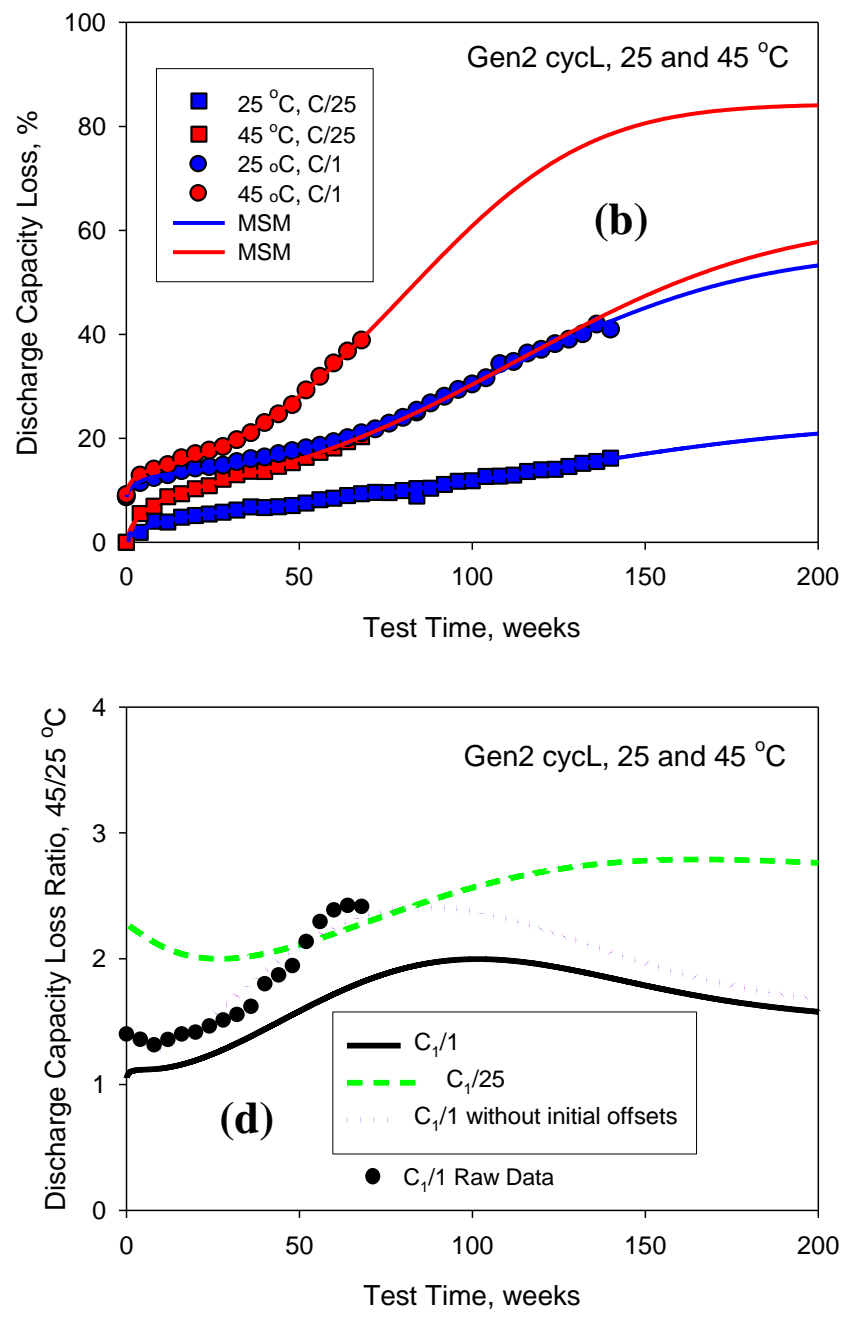

Fig. 3. Analysis of discharge capacity fade data for the various Gen2 test conditions in Fig. 2: (a) calendar-life and (b) cycle-life conditions, with corresponding MSM regression results. Test data: symbols; MSM: solid curves. The $\mathrm{C}_{1} / 1$ values include the polarization offset due to the difference between $\mathrm{C}_{1} / 1$ and $\mathrm{C}_{1} / 25$ cycling rates. Figures (c) and (d) show model results for time-dependent capacity loss curves at various temperature ratios. All regression $\mathrm{R}^{2} \geq 0.9925$. 


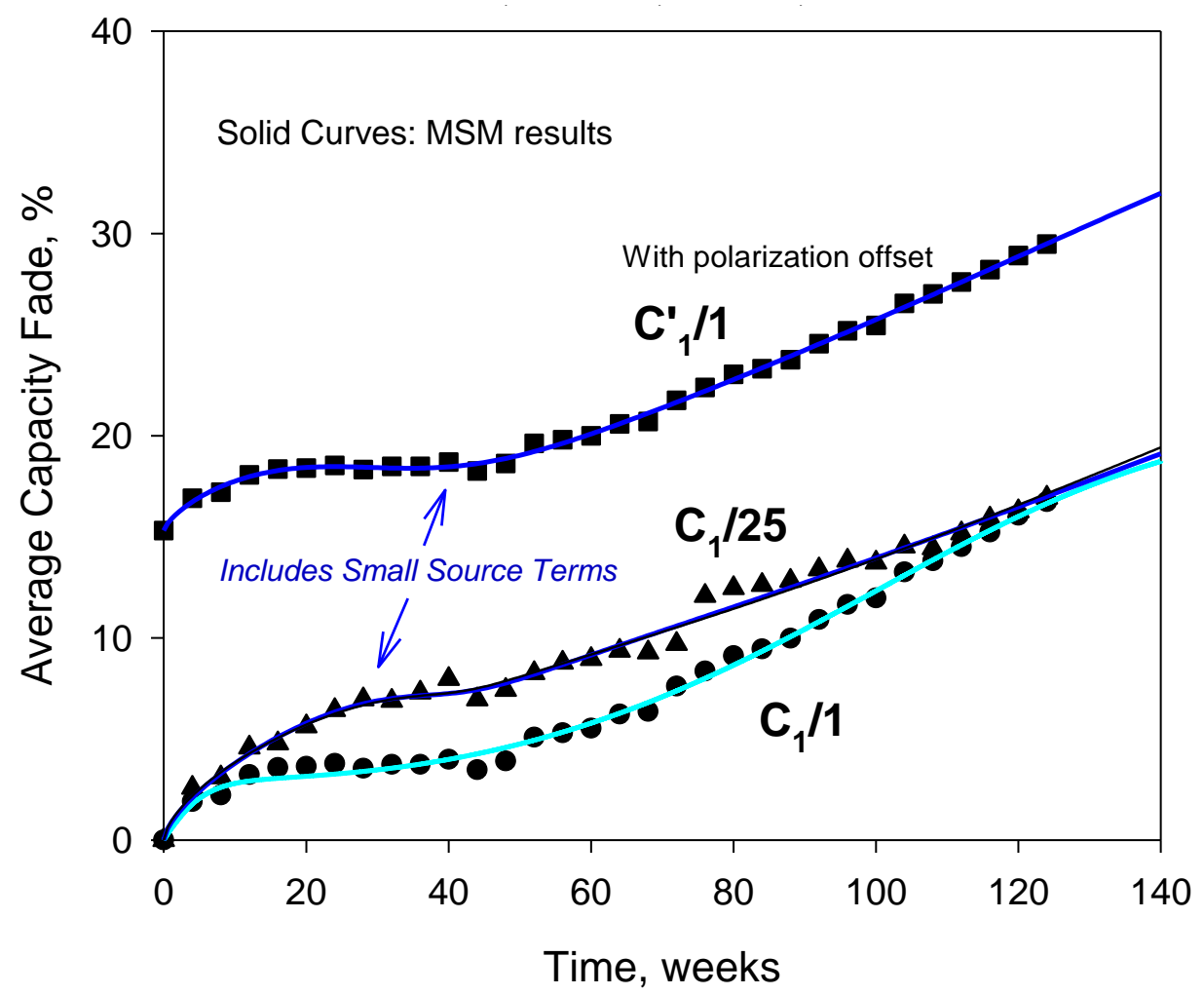

Fig. 4. Discharge capacity fade data for VARC cells tested at INL under cycle-life conditions of $45^{\circ} \mathrm{C}$ and $60 \%$ SOC, with corresponding MSM regression results. Test data: symbols; MSM results: solid curves. The $\mathrm{C}_{1}{ }_{1} / 1$ values include the polarization offset due to the difference between $\mathrm{C}_{1} / 1$ and $\mathrm{C}_{1} / 25$ cycling rates. Regression $R^{2} \geq 0.988$ in all cases. 


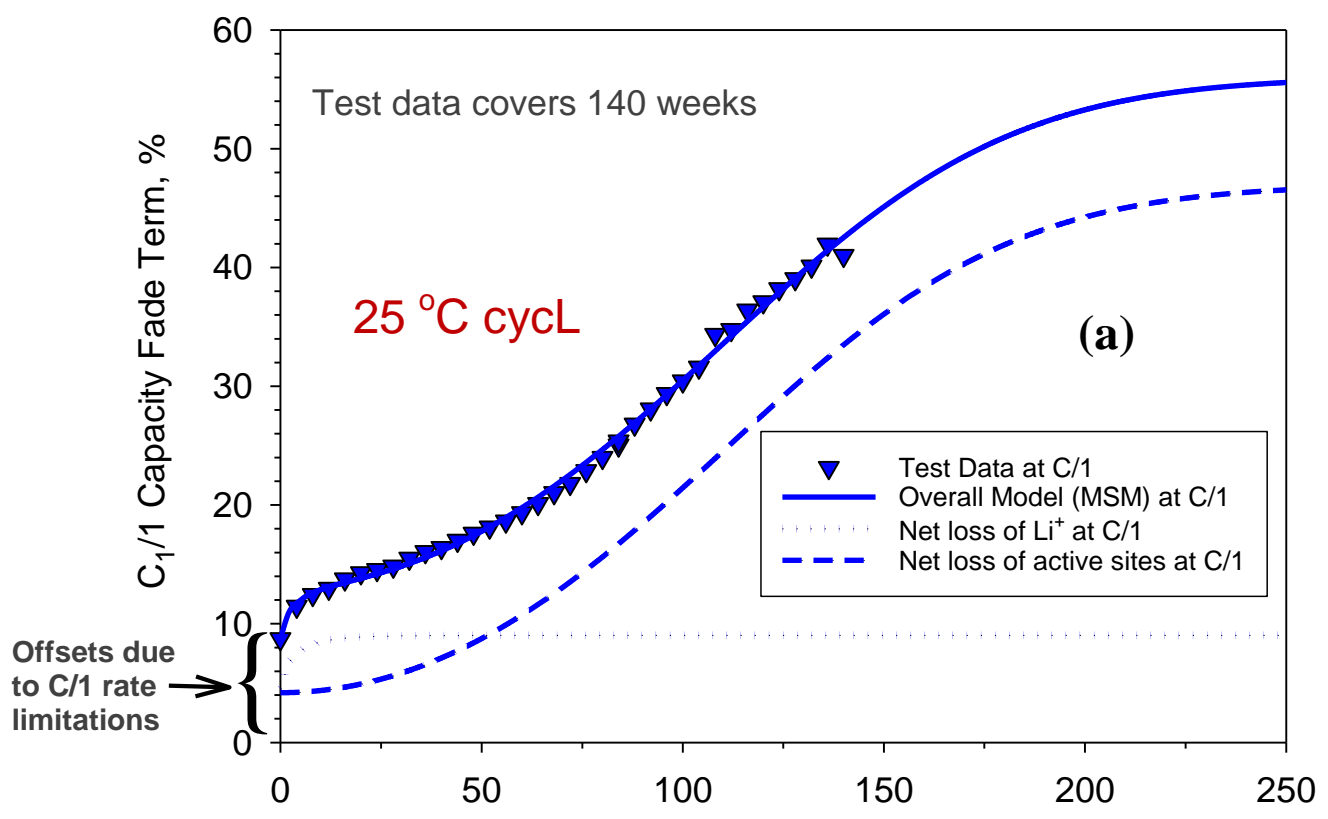

Time, Weeks

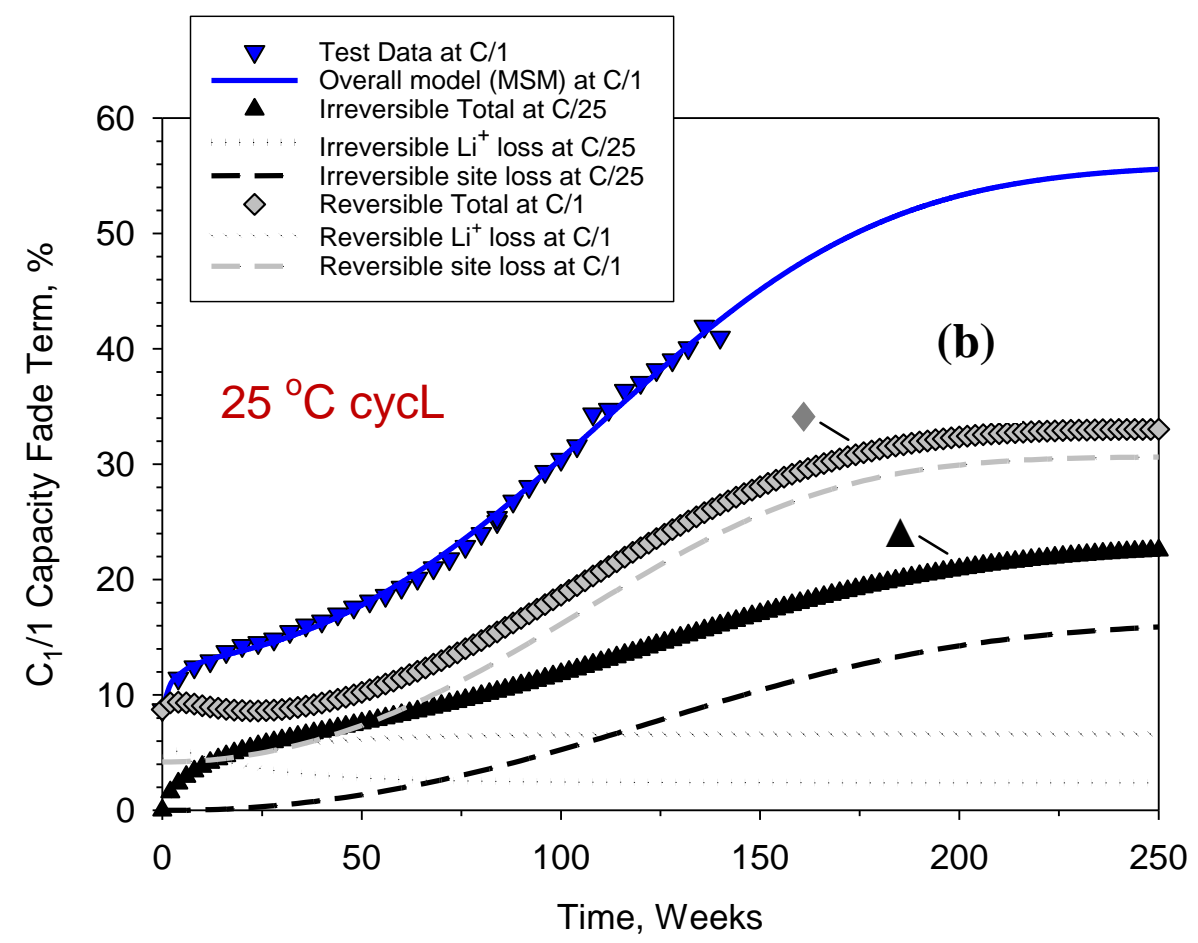

Fig. 5. Summary of $C_{1} / 1$ capacity loss terms for Gen 2 cells cycle-life tested at $25{ }^{\circ} \mathrm{C}$ and $60 \%$ SOC, showing (a) overall and mechanism-wise contributions and (b) irreversible and reversible contributions. Neglecting the BOL offset, irreversible losses dominate during early testing while reversible losses dominate later (well past the 140 week test period). Overall, it is the capacity performance tied to active sites that dominates the effective capacity loss here. 

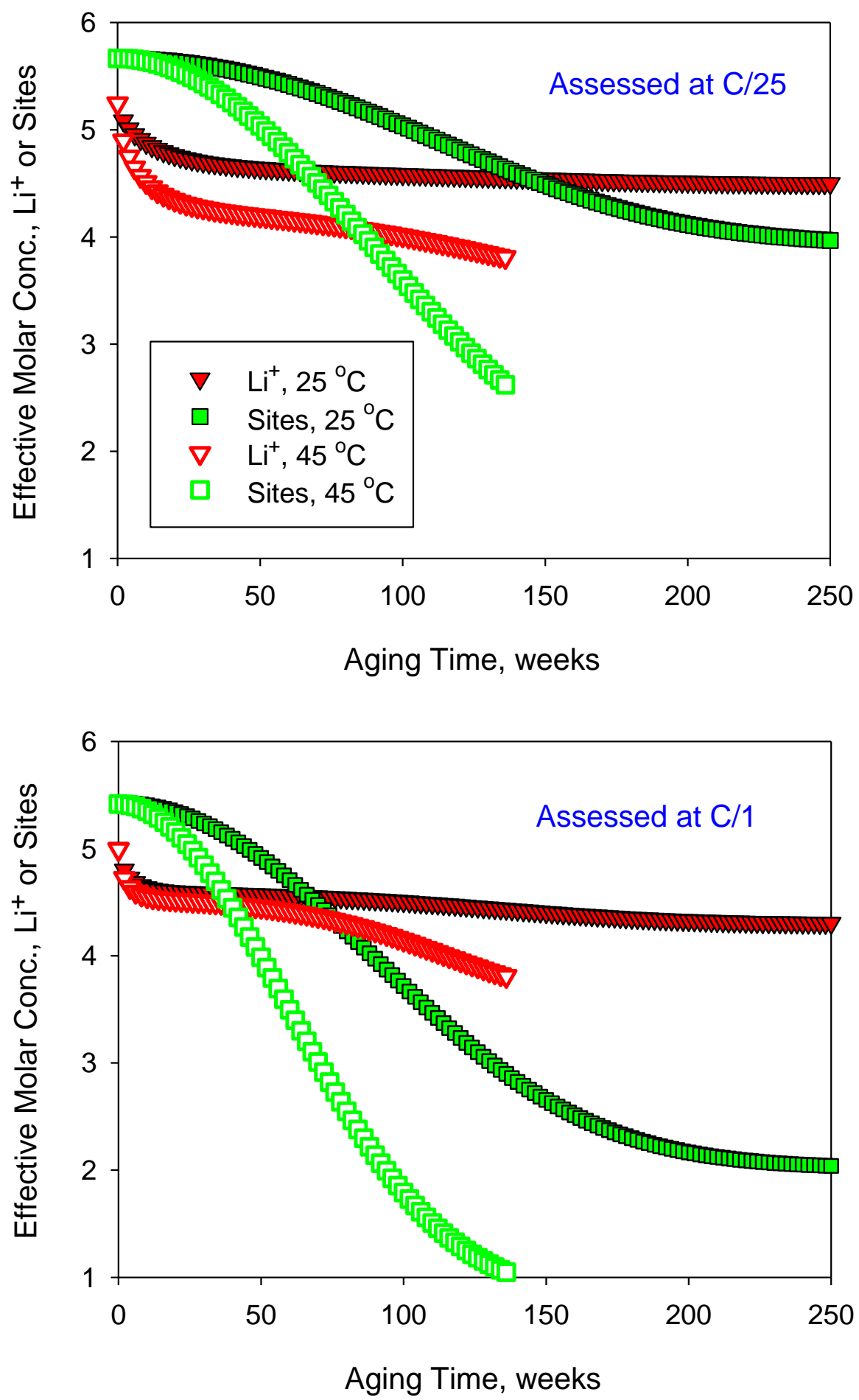

Fig. 6. Detailed analyses from MSM for Gen2 cells cycle-life tested at 25 and $45^{\circ} \mathrm{C}$ and $60 \% \mathrm{SOC}$, comparing $\mathrm{C}_{1} / 25$ and $\mathrm{C}_{1} / 1$ cycling rates. Shown are effective molar concentrations of $\theta$ and $\mathrm{Li}^{+}$ (per FAAS and FALI). Model results span time periods roughly twice that of the corresponding test data. 

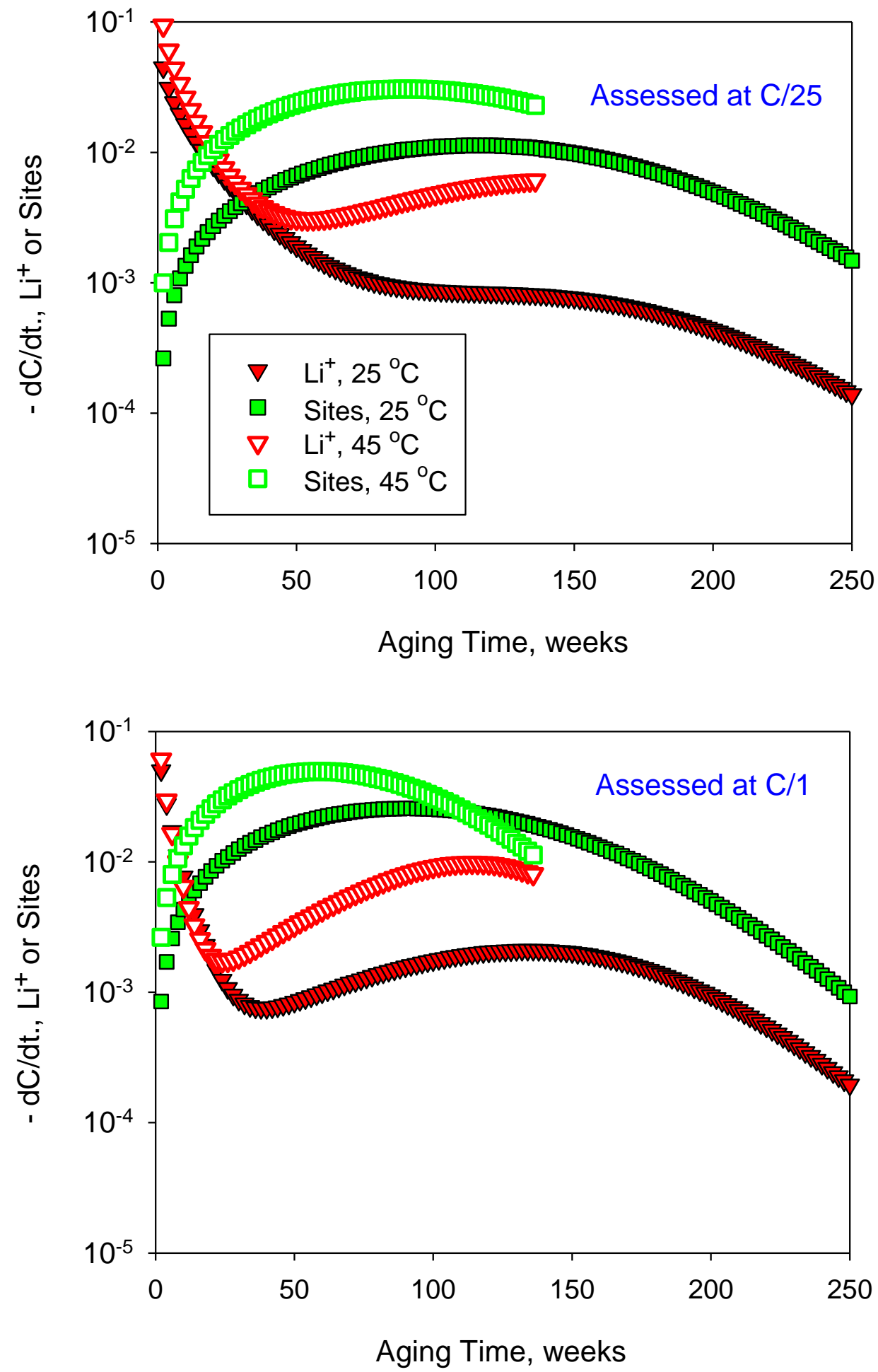

Fig. 7. Rate of change (time derivatives) of the concentration profiles shown in Fig. 5, from MSM analyses of Gen2 cells cycle-life tested at 25 and $45^{\circ} \mathrm{C}$ and $60 \%$ SOC, comparing $\mathrm{C}_{1} / 25$ and $\mathrm{C}_{1} / 1$ cycling rates. Model results span time periods roughly twice that of the corresponding test data. 


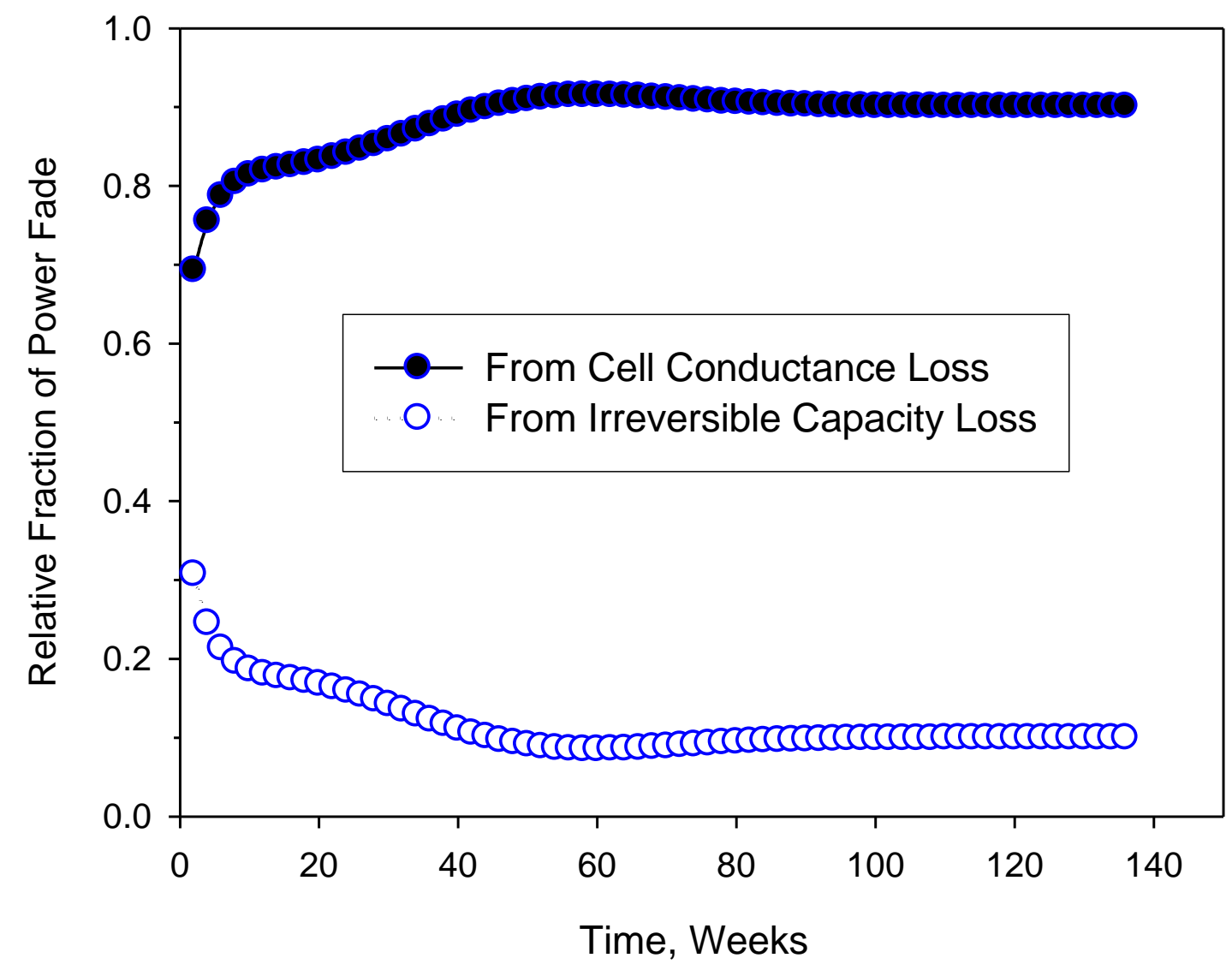

Fig. 8. Additional analyses from MSM for Gen2 cells cycle-life tested at $45{ }^{\circ} \mathrm{C}$ and $60 \%$ SOC, showing the estimated fraction of cell power fade that is due to conductance and capacity losses. 


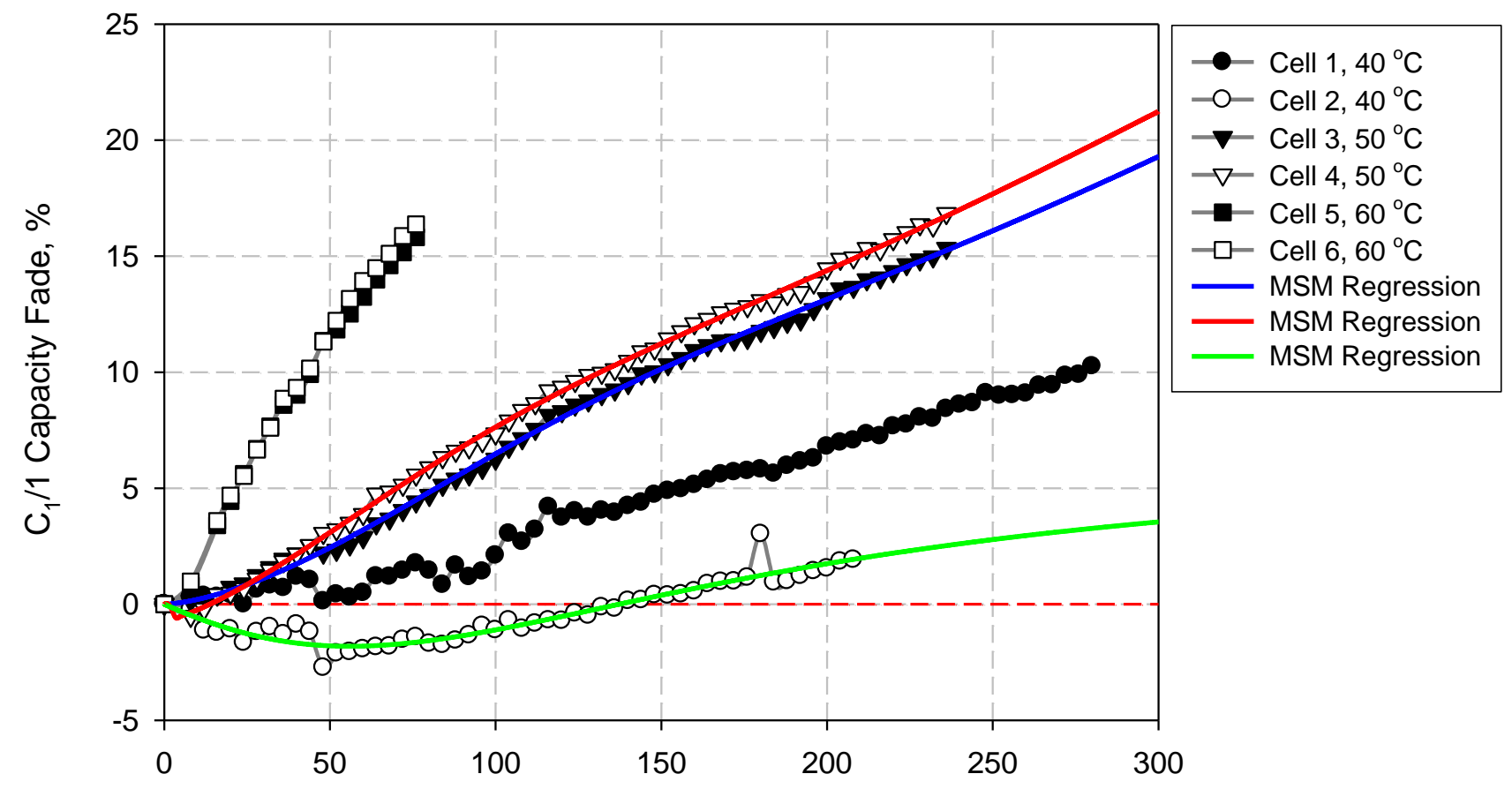

Time, Weeks

Fig. 9. $\mathrm{C}_{1} / 1$ Capacity fade profiles and three-term MSM regression results for selected SAFT highpower cells tested at the INL under calendar-life conditions. Note that MSM results show particularly high fidelity to the data due to the inclusion of $\mathrm{a} \mathrm{Li}^{+}$source term. The data and modeling results indicate that this chemistry exhibits a lithium reserve over time. 


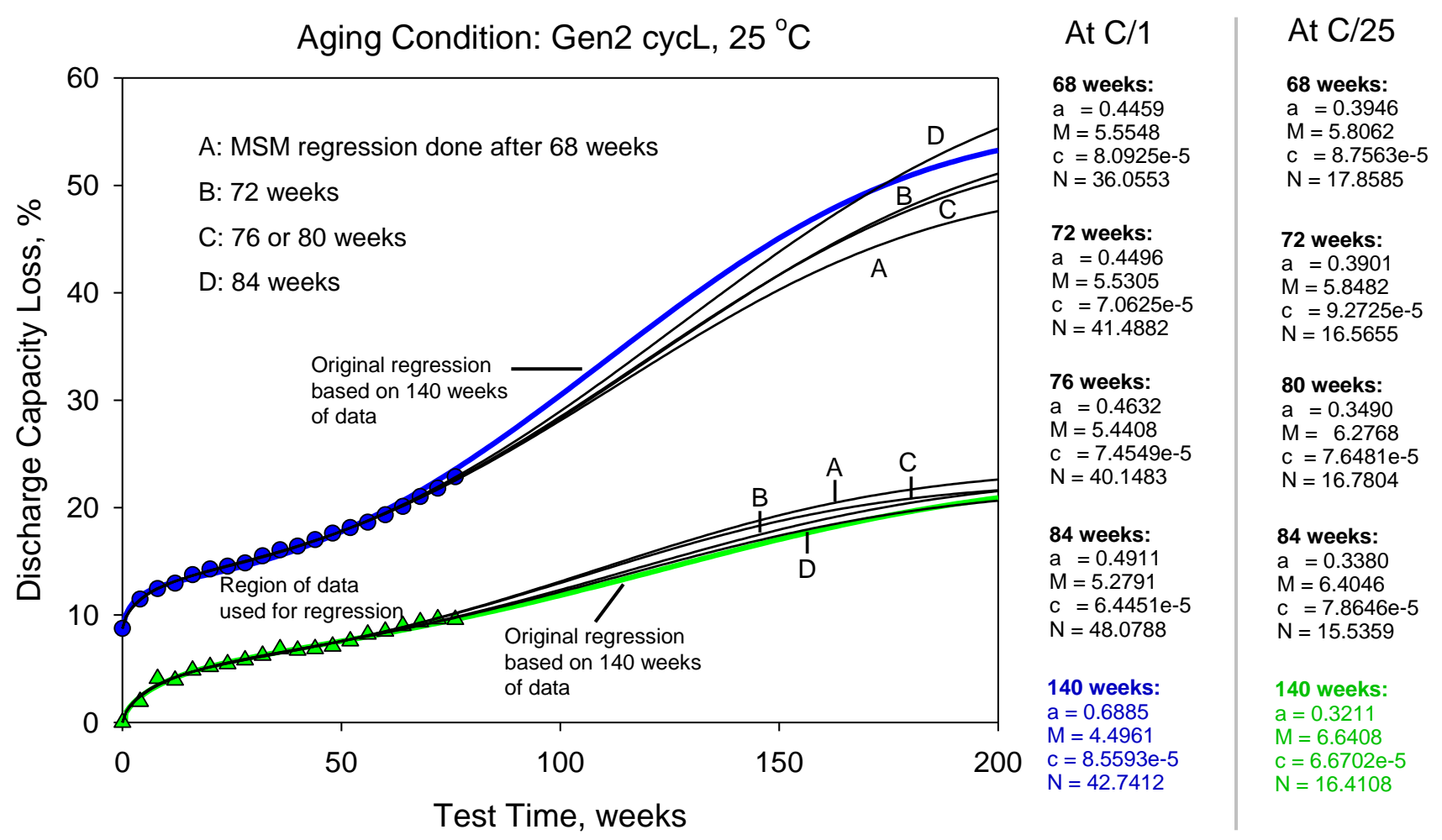

Fig. 10. Results from testing the predictive capabilities of the MSM approach for two representative data sets (Gen2 C/1 and C/25 capacity at cycL testing at $25^{\circ} \mathrm{C}$ ). Approximately the first half of the original 140 weeks of data was used for each regression analysis, and results indicate good predictive capability against the 140 week trend lines for both data sets. Parameters ' $b$ ' and 'd' were set at 0.6 and 2.0, respectively, per Table 2. 